\title{
Towing Tank Testing of Passively Adaptive Composite Tidal Turbine Blades and Comparison to Design Tool
}

\author{
Robynne E. Murray ${ }^{\# 1}$, Stephanie Ordonez-Sanchez*, Kate E. Porter*, Darrel A. Doman, Michael J. Pegg ${ }^{\dagger}$ and Cameron M. \\ Johnstone* \\ \# Department of Mechanical Engineering, Dalhousie University \\ ${ }^{\dagger}$ Department of Process Engineering and Applied Science, Dalhousie University, \\ PO Box 15000, Halifax, Nova Scotia, Canada, B3H 4R2 \\ ${ }^{1}$ r.murray@dal.ca \\ * Energy Systems Research Unit, Department of Mechanical and Aerospace Engineering University of Strathclyde, \\ Glasgow, UK, G1 1 XJ
}

Abstract - Passively adaptive bend-twist (BT) tidal turbine blades made of non-homogeneous composite materials have the potential to reduce the structural loads on turbines so that smaller more cost effective components can be used. Using BT blades can also moderate the demands on the turbine generator above design conditions. This paper presents experimental towing tank test results for an $828 \mathrm{~mm}$ diameter turbine with composite BT blades compared to a turbine with geometrically equivalent rigid aluminum blades. The BT blades were constructed of a graphite-epoxy unidirectional composite material with ply angles of $26.8^{\circ}$ to induce BT coupling, and an epoxy foam core. For steady flow conditions the BT blades were found to have up to $11 \%$ lower thrust loads compared to rigid blades, with the load reductions varying as a function of flow speed and rotational speed. A coupled finite element model-blade element momentum theory design tool was developed to iterate between the structural (deformation and stresses) and hydrodynamic (power and thrust loads) responses of these adaptive composite blades. When compared to the experimental test results, the design tool predictions were within at least $8 \%$ of the experimental results for tip-speed ratios greater than 2.5.

Keywords - Passively adaptive blades, Towing tank tests, Composite blades, Load reductions, Finite element model, Blade element momentum theory

\section{NOMENCLATURE}

BEMT Blade element momentum theory

BT Bend-twist

FEM Finite element model

FSI $\quad$ Fluid structural interaction

HATT Horizontal axis tidal turbines

TGC Torque generating current

TSR, $\lambda \quad$ Tip speed ratio

VP Variable pitch

\section{INTRODUCTION}

Marine renewable energy technologies such as horizontal axis tidal turbines (HATTs) have seen increasing interest in recent years due to a global push for increased renewable energy uptake. However, the high capital and maintenance costs associated with operating turbines in hostile subsea environments currently limits the commercial viability of this technology. Reliability and durability of HATTs are therefore primary concerns due to the high cost to retrieve and maintain a device once it has been 
41 deployed [1]. With blades being critical components with high failure rates [2-4], there has been significant focus on increasing

42 blade robustness through material selection and appropriate engineering design. Turbine blade performance also has a significant 43 effect on the loads experienced by other turbine components, and hence blade design optimization can lead to increased cost 44 effectiveness of the overall turbine.

45 Along with reliability and durability, HATTs need to be designed for the deployment site characteristics. At a typical tidal energy 46 site the flow velocities vary sinusoidally with time, hence the flow speeds corresponding to the maximum available power only occur for a small fraction of the time. Therefore, sizing components to meet this peak power leads to oversized and expensive rotor and drivetrain components $[5,6]$. To maximize the utilization factors of turbine components, developers typically design turbines for flow speeds that are lower than the expected site maximum [7]. Turbine power and loads therefore need to be regulated when the flow velocities at a site exceed design conditions to prevent damage to equipment caused by overloading the turbine blades and structure, and overpowering the generator. Load and power regulation methodologies are dominated in the wind industry by variable pitch (VP) mechanisms, which attach the blade root to the hub and alter the blade pitch (typically feathering the blades to reduce the angle of attack) at high wind speeds. Investigations have shown that VP mechanisms for the tidal energy application can improve power capture by maintaining the optimal angle of attack [8]. However, for subsea applications, VP mechanisms are expensive and prone to failure due to problems with sealing and complex mechanical and electrical control systems [9]. Fixed pitch (FP) blades typically have lower capital and operational costs [10], as well as increased reliability, making them better suited to the harsh tidal environment. Although FP blade systems extract overall less energy, the cost of the energy produced is reduced by 10-20\% [8]. Perhaps the main disadvantage of FP blades is that they are exposed to high thrust loads at high flow speeds because they lack the ability to adapt to changes in environmental conditions. To avoid this problem, loads can be reduced on FP blades using blade designs that passively alter their angle of attack during operation, for example, using tailored composite materials.

Composite materials have a high fatigue tolerance, high strength-to-weight ratio, are corrosion resistant, and have higher damage tolerance than commonly used metal materials [11], making them of interest for components operating in harsh environments [12]. For tidal turbines, as the weight of the blade decreases, the physical demands on the hub and support structure decrease. The equipment requirements to transport, deploy, and retrieve the blades at the tidal site decrease as well [13], resulting in lower capital and operating expenditures. Composite materials are also of increasing interest in industries where the cost effectiveness of a component can be increased by tailoring the structures' mechanical response [13]. By preferentially orientating fibers, components made of composite materials can be designed to exhibit desirable elastic deformation behavior that is not necessarily proportional to the imposed load. For example, the flap-wise bending of a turbine blade can be coupled with span-wise twisting by exploiting the coupled bending and twisting deformation response of composite materials with off-axis plies (bend-twist coupling). Bend-twist (BT) coupling can decrease turbine loads by reducing the angle of attack of the blade as a function of hydrodynamic loading, causing the blade to passively feather and regulate loads. Decreased blade loads result in decreased loads on turbine components (hub, bearings, drive train, etc.) and turbine support structures, hence smaller and less expensive components can be used. BT blades can also potentially regulate power above design conditions, reducing the demands and increasing the utilization factor of the turbine generator. 
78 reduction in thrust loads and up to $5 \%$ increase in the power coefficient for an $8 \mathrm{~m}$ blade with a BT composite spar with a tip twist of $8.6^{\circ}$ toward feather and tip displacement of $1.48 \mathrm{~m}$. Similar outcomes were reported using a modified blade element momentum theory (BEMT) code, however, numerical results were not verified experimentally. Motley and Barber [15] used an iterative boundary element method and finite element method solver to model a two bladed, $20 \mathrm{~m}$ diameter, variable speed-VP turbine with BT composite blades. They showed that if the blades were designed to passively twist toward stall the overall power capture increased but the turbine required the use of the VP mechanism at a lower flow speed and had higher blade loads. Blades that passively twisted to feather resulted in decreased power capture but delayed the onset of mechanical pitching and resulted in lower blade loads before the onset of active control. Further studies using the design tool outlined in [15] showed that passively adaptive BT blades could increase annual power capture by delaying the onset of cavitation, thus enabling the use of larger blades operating at higher rotational speeds, increasing the annual energy capture [16]. SCHOTTEL [17] tested a 4 m diameter rotor on the front of a tug boat and found that BT composite blades had up to 50\% lower thrust loads than equivalent rigid blades, however, the composite layup and blade geometry were proprietary. Wada et al. [18] tested two sets of composite blades in a towing tank, one set that were torsionally rigid (fully laminated with carbon fiber composite) and one set that were torsionally elastic (spar and skins made of carbon fiber composite and epoxy resin core) and found that the power coefficient and coefficient of resistance (analogous to the thrust coefficient) both decreased for the more flexible blades. The blade deformation was also calculated by FSI and the simulations were compared to the experimental results. However, there was no mention of composite layups or BT coupling, and the FSI under-predicted the twist angle significantly (experimental pitch angle change of about $2.6^{\circ}$ and an FSI prediction of $4^{\circ}$ ). BT coupling has also been used in both the propulsion and wind energy industries; a full discussion of these applications can be found in [19].

Although there has been research done in the area, there is currently a lack of experimental data relating the performance of a tidal energy turbine with BT coupled blades to the composite design. Without experimental data enabling sufficient model verification, high safety factors are required for turbine and blade design to compensate for the uncertainty in the turbine performance. The objective of this work was to quantify the performance of an $828 \mathrm{~mm}$ diameter three-bladed HATT with BT composite blades in the towing tank at the Kelvin Hydrodynamics Laboratory (University of Strathclyde). The composite blade design and geometry are detailed in Section 2. Performance results of the turbine with composite blades were compared to the same turbine operated with geometrically equivalent rigid aluminum blades. These tests are aimed to increase confidence in turbine performance modelling by providing model verification data for a range of operating conditions. Results of these tests, shown in Section 4, were also used to verify a coupled finite element model (FEM)-BEMT design tool. Design tool verification is an important step in the research and development process as it facilitates investigation into effects of BT composite blades that are not pragmatic to test experimentally. Details of the design tool are given in Section 3, and the final conclusions and remarks of this investigation are presented in Section 5.

\section{EXPERIMENTAL SETUP}

A small-scale turbine with aluminum and composite BT blades was tested experimentally, allowing for cost effective design tool verification, as is typically done for early stage tidal energy device development [20]. An $828 \mathrm{~mm}$ diameter turbine was chosen to compromise between maximizing the chord-Reynolds number and keeping the towing tank blockage ratio reasonably low. This section outlines the blade and turbine geometry, the composite blade design, and the test program and conditions. 
Figure 1 shows the turbine and support structure designed and manufactured at Cardiff University (details can be found in [21]).

The turbine stanchion was mounted to the towing tank carriage at the Kelvin Hydrodynamics Laboratory by two brackets with the center of the hub $1.0 \mathrm{~m}$ below the free surface of the water. The turbine was driven at a constant rotational speed using a Rexroth IndraDyn T Synchronous-Torquemotors motor with a rated power of $0.6 \mathrm{~kW}$, rated torque of $22.5 \mathrm{Nm}$, and rated speed of 350 RPM [22]. Data was logged at $137 \mathrm{~Hz}$ using a Cambridge Electronic Design Power 1401 DAQ and the DAQ program, Spike, and exported as text files for post processing in $\mathrm{MATLAB}^{\circledR}$. The rotor rotational speed was obtained from a position output from the motor drive, which, using the time stamp recorded in Spike, enabled a calculation of the number of rotations in a given time period. The carriage speed was a direct output from the carriage operating system.
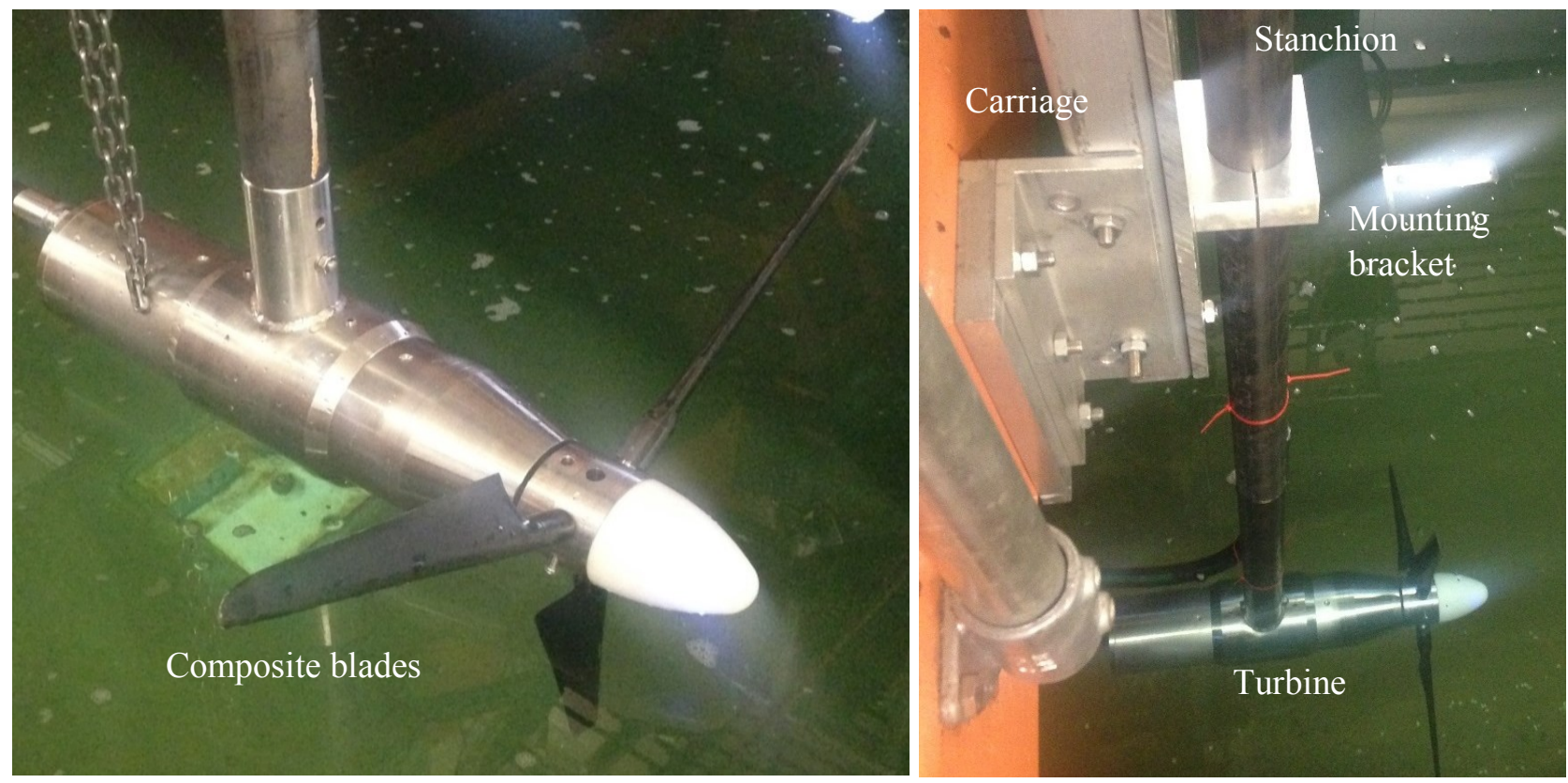

Figure 1 Cardiff University turbine with composite BT blades.

Along with the carriage speed and rotor rotational speed, the main measurements of interest in these tests were the torque and thrust on the rotor. The torque produced by the rotor blades was obtained from the torque generating current (TGC) output by the motor. The rotor torque was calculated by subtracting the TGC required to rotate the turbine at a particular speed without the blades on, from the TGC recorded for each test, thus effectively giving the torque produced by the hydrodynamic loads on the blades. The required TGC to spin the turbine and overcome friction in the drive shaft was a function of the rotational speed of the motor, and was calibrated by the team at Cardiff University prior to testing. More details on the TGC and rotor torque calculations can be found in [23].

To measure the rotor thrust, the turbine stanchion was instrumented with a $5 \mathrm{~mm}$ long, Y11-FA-5-120 strain gauge, with a 119.9 Ohm resistance and $2.07 \pm 1 \%$ gauge factor, which was located $1.5 \mathrm{~m}$ from the mid hub height ( $0.5 \mathrm{~m}$ above the free surface). The thrust sensor was calibrated by applying known loads ranging from 0 to $20 \mathrm{~kg}$ (in increments of $0.5 \mathrm{~kg}$ ) to a lever arm and measuring the output voltage over a range from 0 to $10 \mathrm{~V}$. The calibration showed the strain measurement to be highly linear with a coefficient of determination, $\mathrm{R}^{2}$, of 0.9999 . To isolate the thrust loads on the blades from the loads on the entire system, tests were run with only the hub and nose cone (no blades) at a range of flow speeds. This thrust value was then subtracted from the mean thrust for each test, quantifying the thrust loads on the rotor blades. 
The turbine had a hub radius of $50 \mathrm{~mm}$ and blade length of $364 \mathrm{~mm}$, giving a rotor radius of $414 \mathrm{~mm}$, as shown in Figure 2. A 15 $\mathrm{mm}$ diameter stainless steel cylindrical root connection at the base of the blades was inserted into a slot in the hub, and the root pitch setting of the blade was constrained at $28.89^{\circ}$ by a $4.5 \mathrm{~mm}$ diameter grub screw that fit into a slot on the blade root. The uncertainty in the pitch setting was estimated based on the $\pm 0.05 \mathrm{~mm}$ machining uncertainty of the slot, equating to $\pm 0.38^{\circ}$ of uncertainty in the blade root pitch setting. Uncertainty in the turbine radius was based on the machining accuracy of the hub components $( \pm 0.5 \mathrm{~mm})$. The uncertainty in the composite blade length was estimated to be $\pm 5 \mu \mathrm{m}$ based on the resolution of a coordinate measuring machine (CMM) which was used to scan the final composite blade geometry as manufactured. The uncertainty in the aluminum blade length was from the $\pm 10 \mu \mathrm{m}$ precision of the $\mathrm{CNC}$ machine that was used to manufacture them. These uncertainty values are used in Section 4 to estimate the experimental uncertainty of the measured parameters.

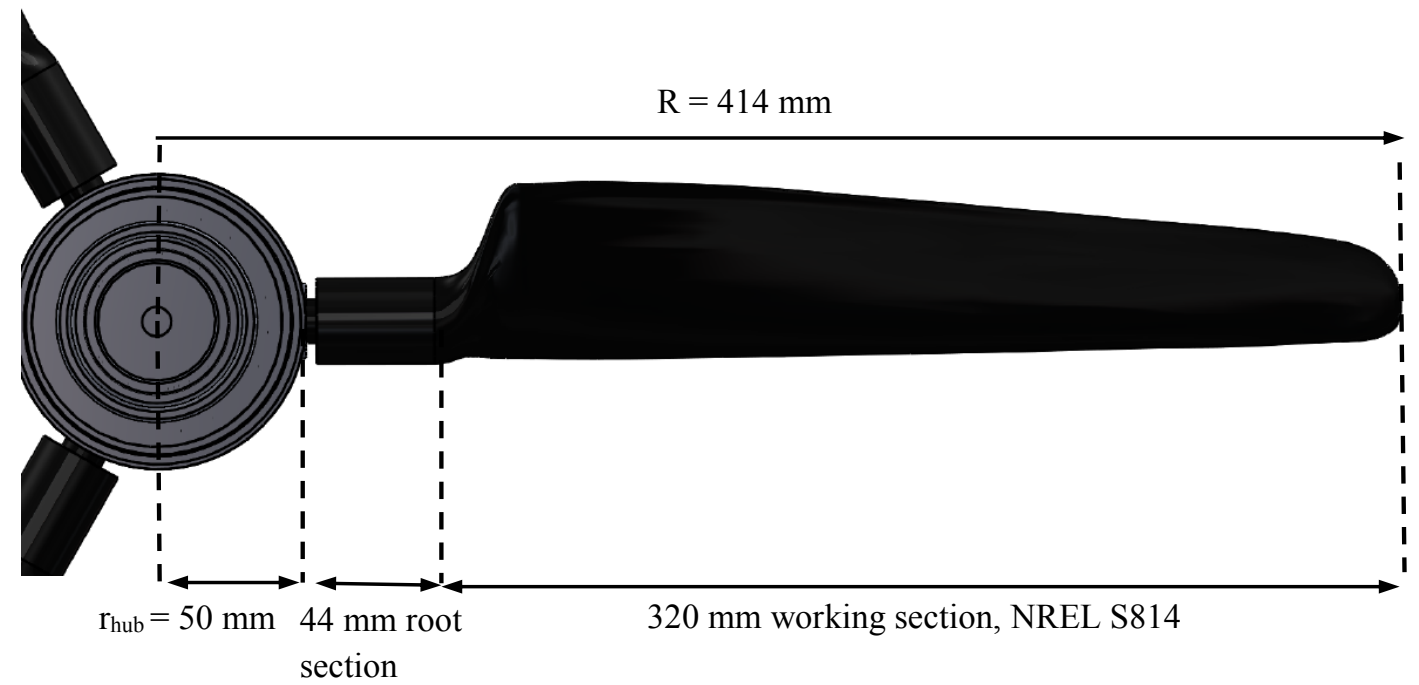

Figure 2 Schematic of turbine and blade dimensions.

The blade geometry relative to the turbine is given in Table 1 . The pre-twist and chord of the blades were based on a blade geometry that was developed for previous test campaigns [24]. The shaded grey part of the table denotes the hub and root section of the rotor, and the unshaded part of the table denotes the working section of the blade. For this system, the blockage ratio was calculated by taking the ratio of rotor area to tank cross sectional area, and was found to be $5.26 \%$. Based on literature summarized in [25], this was not considered large enough to require correction.

Table 1: Turbine and blade geometry for design tool verification.

\begin{tabular}{ccccc}
\hline Turbine radius (mm) & Blade length $(\mathbf{m m})$ & \multicolumn{1}{c}{ Blade twist (Degrees) } & Blade chord (mm) & Section shape \\
\hline 0 & 0 & N/A & N/A & Hub \\
50 & 0 & N/A & 15 & Circular root \\
54 & 4 & N/A & 15 & Circular root \\
94 & 44 & N/A & 29 & Circular root \\
\hline 110 & 60 & N/A & N/A & Lofted (ellipse)
\end{tabular}




\begin{tabular}{ccccc}
120 & 66 & N/A & N/A & Lofted (ellipse) \\
122 & 72 & 0 & 64.3 & NREL S814 \\
147 & 97 & -4.38 & 62.9 & NREL S814 \\
182 & 132 & -10.74 & 59.8 & NREL S814 \\
216 & 166 & -14.8 & 56.0 & NREL S814 \\
249 & 199 & -17.33 & 51.6 & NREL S814 \\
284 & 234 & -18.91 & 47.3 & NREL S814 \\
319 & 269 & -19.75 & 42.6 & NREL S814 \\
354 & 304 & -20.39 & 38.1 & NREL S814 \\
388 & 338 & -20.87 & 33.7 & NREL S814 \\
414 & 364 & -21.11 & 24.9 & NREL S814 \\
\hline
\end{tabular}

\subsection{Blade design and construction}

A FEM-BEMT design tool with a composite material failure analysis, outlined in Section 3, was used to guide the design (ply angles, ply thicknesses, and materials) of the BT composite blades that were tested in the towing tank. The objective of the blade design process was to maximize tip twist and minimize stress, hence maximizing thrust load reductions while still meeting sufficient material strength requirements. More detail on the blade design process can be found in [25].

The composite blades were manufactured by Airborne Marine (Netherlands). The core of the working section of the blade was constructed of Sicomin PB 250 (density of $250 \mathrm{~kg} / \mathrm{m}^{3}$ ) closed-cell foam and the blade skins were constructed of a single layer of uniform $0.20 \mathrm{~mm}$ thick unidirectional graphite-epoxy composite. Although glass fiber composites are generally less stiff than graphite fiber composites, glass composites have a higher transverse stiffness relative to the longitudinal stiffness. This means that although a blade with glass fiber materials will have greater bending displacement, the BT coupling response will be lower than a graphite composite blade, hence graphite-epoxy composites was chosen for these blades. The composite skins had plies oriented at an angle to the long axis of the blade with a mirrored layup (described in [26]) to induce BT coupling. The working section of the three blades had average fiber angles of $26.8^{\circ}$, with a standard deviation of $0.8^{\circ}$ (ply angles were verified optically after manufacturing). These ply angles were based on an optimization exercise using the design tool that indicated that ply angles of approximately $30^{\circ}$ maximized the BT response of a composite blade. This variance in ply angles is considered small and was attributed to manufacturing challenges associated with the relatively high surface curvature of the small-scale blades.

At the blade root, the $0.2 \mathrm{~mm}$ thick ply layer from the working section of the blade was extended to cover a $25.40 \mathrm{~mm}$ (1-inch) diameter 316 stainless steel cylindrical insert (used to attach the blades for testing). The root section was laid up with six additional layers of $0.2 \mathrm{~mm}$ thick composite with alternating ply angles of $\left[15^{\circ},-15^{\circ}\right]$ (increasing the composite thickness at the root to 1.6 $\mathrm{mm}$ for added strength). An additional $15 \mathrm{~mm}$ diameter cylindrical steel section protruded from the end of the blade and fit into a slot in the hub to attach the blades. This steel section was offset by $4 \mathrm{~mm}$ from the surface of the hub, resulting in a total of a 44 $\mathrm{mm}$ long circular root section ( $25.40 \mathrm{~mm}$ diameter stepped down to $15 \mathrm{~mm}$ diameter) exposed to flow, as shown in Figure 2 . Material properties are given in Table 2, and the strength parameters used in the design tool failure analysis are from [27]. 
Table 2: Composite and epoxy material properties [28, 29$].$

\begin{tabular}{llll}
\hline Graphite-epoxy Properties & \multicolumn{3}{c}{ Sicomin Epoxy Properties } \\
\hline Young's modulus, longitudinal & $137 \mathrm{GPa}$ & Density & $250 \mathrm{~kg} / \mathrm{m}^{3}$ \\
Young's Modulus, transverse & $7.8 \mathrm{GPa}$ & Compressive modulus & $0.0189 \mathrm{GPa}$ \\
Shear modulus & $3.9 \mathrm{GPa}$ & Shear modulus & $0.0073 \mathrm{GPa}$ \\
Poisson's Ratio & 0.335 & Poisson's Ratio & 0.3 \\
Longitudinal tensile strength & $1.5 \mathrm{GPa}$ & & \\
Transverse tensile strength & $0.04 \mathrm{GPa}$ & & \\
Longitudinal compressive strength & $1.5 \mathrm{GPa}$ & & \\
Transverse compressive strength & $0.246 \mathrm{GPa}$ & & \\
Shear strength & $0.068 \mathrm{GPa}$ & & \\
\hline
\end{tabular}

184 After the blades were manufactured, a CMM was used to scan the composite blade geometry to identify any features or effects that were not present in the original blade CAD model. The CMM had a resolution of $5 \mu \mathrm{m}$ and a ruby measurement probe with a diameter of $1.5 \mathrm{~mm}$. Measurements of the airfoil sections were taken at 17 span-wise locations in $0.127 \mathrm{~mm}$ increments around each cross-section. Figure 3 shows the cross section of the composite blade at $68 \mathrm{~mm}$ from the base, compared to the theoretical

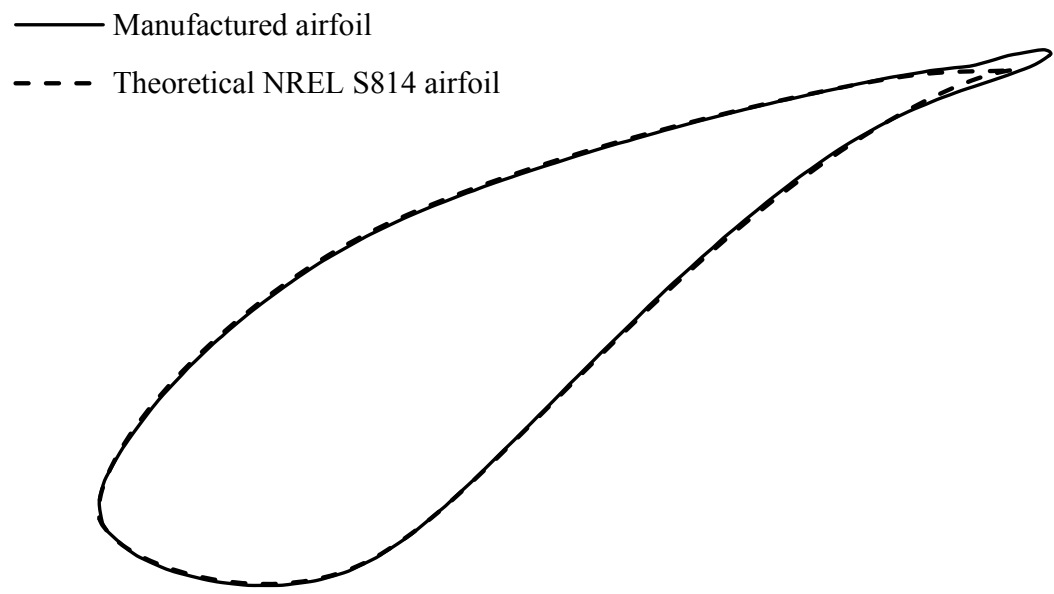

Figure 3 Blade CMM scan compared to theoretical NREL S814 airfoil.

Figure 3 shows the theoretical NREL S814 airfoil and the composite blade airfoil after manufacturing for one of the blades, highlighting an altered trailing edge. Due to the small size of the blades and the mirror layup required for BT coupling, an additional $5 \mathrm{~mm}$ section was required on the trailing edge to bond the composite from the upper and lower surfaces of the blade. To give a baseline from which to compare the BT blade performance, aluminum blades were manufactured from a CAD model that was constructed using section profiles obtained with the CMM scan of the composite blades. This ensured that any effects of the altered trailing edge of the composite blades would be negligible compared to the effects of BT coupling when compared to the aluminum blade performance. The aluminum blades were manufactured using a 5-axis $\mathrm{CNC}$ machine. After manufacturing, the surface roughness of the blades was measured using a hand held Mahr Federal Pocket Surf III, with a resolution of $\pm 0.01 \mu \mathrm{m}$, and found to be at worst $4 \mu \mathrm{m}$ (average groove depth) and $25 \mu \mathrm{m}$ (maximum peak to valley groove depth). Epoxy was applied to 
final surface finish was similar to that of the composite blades. The manufacturing process and surface finishing procedure gave a total uncertainty in the blade airfoil thickness of $\pm 0.05 \mathrm{~mm}$. The aluminum blades were considered rigid relative to the composite blades, as previous static bending tests showed the aluminum blades had $84 \%$ less bending displacement than the composite

\subsection{Test procedures}

For each test, the carriage was drawn down the length of the towing tank at a constant velocity and the rotational velocity of the turbine was fixed, producing data for a single tip-speed ratio (TSR, $\lambda$ ). Carriage speeds of $1.0 \mathrm{~m} / \mathrm{s}$ and $0.85 \mathrm{~m} / \mathrm{s}$ were tested and the turbine rotational speeds were varied between 50 and 110 RPM in increments of 5 RPM. Due to limitations in the torque of the motor, the carriage speed and rotational speed of the turbine were limited to below $1.0 \mathrm{~m} / \mathrm{s}$ and $110 \mathrm{RPM}$. At rotational and carriage speeds above this, the motor was unable to maintain the rotor torque at a steady value. The Reynolds numbers for these tests (chord Reynolds numbers ranging from $8 \times 10^{4}$ to $1.7 \times 10^{5}$ based on a chord length of $0.047 \mathrm{~m}$ at $75 \%$ radius) were an order of magnitude lower than those expected at full scale. This has implications on the performance of the airfoil, as discussed in [30], however, these tests are still expected to provide useful insight into the performance of composite BT blades in steady flow conditions.

The raw carriage velocity, rotor torque, thrust, and rotational speed signals were obtained from the DAQ at a frequency of 137 Hz. The noise in these signals had a zero mean, therefore they were averaged over an integer number of rotor revolutions in the steady region of each test (once the rotor and carriage velocities were stable, resulting in a test length of approximately 30 seconds). Calibration factors determined prior to testing for the thrust and torque measurements were applied to the data to convert it to engineering units.

\section{DESIGN TOOL}

Design methodologies for BT blades require the consideration of fluid and structure interactions due to the increased flexibility of BT blades. This section outlines a design tool developed to account for the coupled hydrodynamic and structural performance of a turbine with BT composite blades. The design tool uses a MATLAB ${ }^{\circledR}$ interface to iterate between a BEMT code and FEM. In this case, BEMT was used as opposed to more complex modeling approaches such as computational fluid dynamics codes, as this design tool was intended for early stage blade design where low computational cost is a priority.

To model a HATT with BT blades, the blade geometry, airfoil data, operating conditions (flow and rotational velocities), and composite layup and material properties, are input to the design tool. The BEMT code (detailed in Section 3.2) is executed to estimate the blade loads, which are applied to nodes in a FEM (detailed in Section 3.1). The FEM is then executed and the composite blade displacements and stresses are computed from elemental and nodal outputs. The induced twist of the blade due to BT coupling is calculated from the nodal displacements at increments along the blade span. The induced twist predicted by the FEM is then added to the pre-twist of the baseline blade, resulting in an updated blade geometry after each iteration. A change in the blade pre-twist geometry alters the BEMT-predicted blade loads, hence an iterative process between the FEM and BEMT is required to estimate the final turbine performance. With the induced twist as the convergence criterion, the iterations are executed until the induced twist of the blade for the current iteration was within $0.05 \%$ of the previous iteration. A $0.05 \%$ difference in the induced twist equates to less than $0.1 \%$ difference in the rotor thrust, which was considered within the sensitivity of the design tool. Sections 3.1 to 3.3 describe the setup of the FEM and BEMT codes and the composite failure analysis used to model the small-scale HATT tested in the towing tank. In previous work the FEM and BEMT components of the design tool were verified 
independently [31]. The FEM was verified through static bending tests of the BT blades, and the BEMT code was verified through a comparison to towing tank test results of a $1 / 20^{\text {th }}$ scale HATT with rigid aluminum blades. A full description of the design tool, including a process flow chart and initial verifications, can be found in [31].

\subsection{Finite element model}

The FEM component of the coupled FEM-BEMT design tool was developed using the finite element code Altair $^{\circledR}$ RADIOSS $^{\circledR}$ [32]. The blade core was modeled using tetrahedral 3D elements and the composite skin of the blade was modeled using COMPG 2D quadrilateral shell elements. A total of $16,2002 \mathrm{~mm}$ 2D shell elements were used, which was chosen based on a mesh convergence study which showed that elements with edge lengths of less than $3 \mathrm{~mm}$ produced converging results within reasonable computational time. The interface nodes between the 2D mesh for the blade skin and the 3D mesh for the blade core were tied, hence it was assumed that no slipping occurred between the blade core and skin. The blade root, including attachments such as bolts and inserts, were not included in the FEM, and the blade was constrained in all degrees of freedom at the root. The blade mesh is shown in Figure 4.

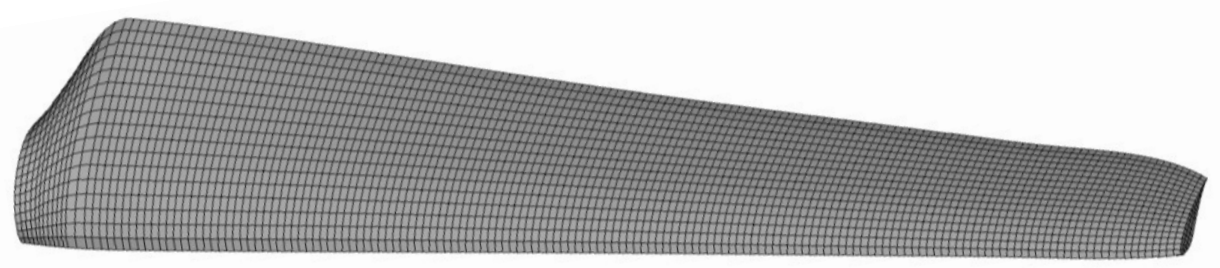

The HyperLaminate module in RADIOSS ${ }^{\circledR}$ was used to define the ply thickness and fiber angle of the composite skins. To model the composite skin, the MAT8 anisotropic constitutive material model was used, which considers the material properties in the longitudinal (fiber) and transverse (matrix) directions in both tension and compression. Foam materials exhibit a non-linear stressstrain relationship after an initial linear deformation period [33] and can be complicated to model. From a preliminary FEM, the maximum expected strain in the blade foam core was estimated to be approximately $0.006 \mathrm{~m} / \mathrm{m}$. Due to the lack of available stress-strain data for the Sicomin foam at the manufactured density of $250 \mathrm{~kg} / \mathrm{m}^{3}$, curves for both higher [34] and lower [33] density epoxy foams were referenced. A strain of $0.006 \mathrm{~m} / \mathrm{m}$ was in the linear range of the stress-strain curves for both the higher and lower density foams $(0.27 \%$ in the linear range for the higher density foam and $0.81 \%$ for the low density foam). Therefore, it was assumed that it would also be in the linear range for the $250 \mathrm{~kg} / \mathrm{m}^{3}$ epoxy foam and was modeled as an isotropic linear elastic material, MAT1. To estimate the material properties for the $250 \mathrm{~kg} / \mathrm{m}^{3}$ foam, a linear interpolation was done between the higher and lower density epoxy foams. The two materials used for this calculation had densities of $120 \mathrm{~kg} / \mathrm{m}^{3}[33] \mathrm{and} 300 \mathrm{~kg} / \mathrm{m}^{3}$ 
[34], with Young's Modulus' of $0.0045 \mathrm{GPa}$ and $0.0245 \mathrm{GPa}$, respectively, giving a Young's Modulus for the $250 \mathrm{~kg} / \mathrm{m}^{3}$ foam of $0.018 \mathrm{GPa}$. It was assumed that the density of the foam was constant over the entire blade.

Axial and tangential loads calculated by the BEMT code were applied to nodes in the FEM at the aerodynamic centre of each blade element cross section along the span, as shown in Figure 5. The pitching moment was neglected due to the lack of moment coefficient data for the NREL S814 airfoil at the operational Reynolds numbers. Based on XFOIL results for several angles of attack, the moment coefficients were found to be small compared to the lift and drag coefficients for the NREL S814 airfoil and were typically negative (resulting in a moment causing feathering). A similar statement was made by Maheri [35].

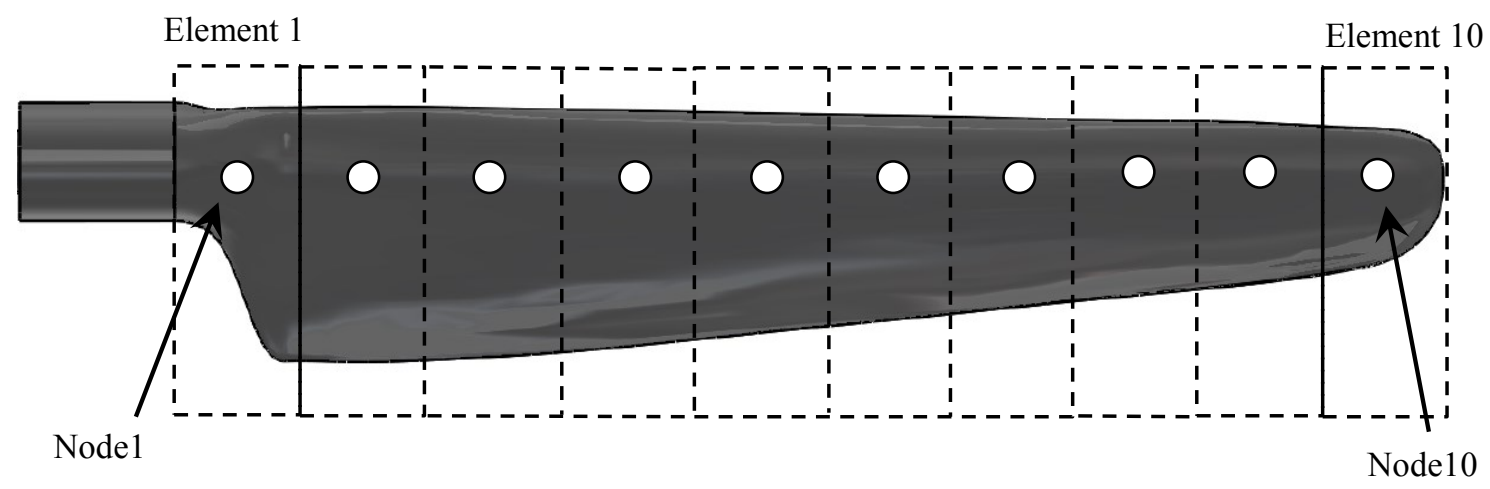

Figure 5 Span-wise loads in FEM for 10 blade elements.

\subsection{Blade element momentum theory}

A BEMT code was developed by Nevalainen [36] based on the original BEMT published by Glauert [37] and altered for HATT following the method outlined by Masters and Orme [38]. This code was used to predict the thrust and torque for each blade element shown in Figure 5. Results of a convergence study showed that 10 blade elements produced a converged BEMT solution in minimal computational time.

To improve the accuracy and account for hydrodynamic effects which are neglected in the baseline BEMT, corrections were applied. Prandtl's tip and hub loss correction factors [39] were used to account for three dimensional effects such as tip and hub losses due to vortex shedding. The Buhl high induction correction [40] was used to correct for cases in which the rotor was heavily loaded (axial induction factors greater than 0.4 ). This correction fits a curve to experimentally obtained thrust coefficients for values greater than a critical value of the axial induction factor. As well, the Viterna-Corrigan post stall correction was added to compensate for the degraded lift observed at high angles of attack (low TSRs). The Viterna-Corrigan post stall model assumes that the blade behaves like a flat plate when fully stalled [41], and the stall lift and drag coefficients are estimated based on the maximum drag coefficient in the fully stalled regime, the lift and drag coefficients at the stall angle, and the aspect ratio of the blade. The combination of these BEMT corrections have been shown to improve the BEMT code accuracy for tidal turbines [40]. Only the working section of the blades were considered in BEMT. A full description of BEMT and corrections used for HATTs can be found in [38].

Typically, airfoil data obtained using computational tools such as XFOIL [42] are used in BEMT codes [43]. However, in this case, experimental airfoil data was used because at the range of Reynolds numbers tested in the towing tank, XFOIL did not converge on a solution at certain angles of attack for the NREL S814 airfoil. Milne [44] proposed that this is due to an inability to predict the point of laminar separation and turbulent reattachment which occur on both the pressure and suction surfaces for 
this relatively thick NREL S814 airfoil (24\% thickness). Airfoil lift and drag data obtained in the flume at Swansea University by Togneri et al. [45] at a Reynolds number of $5 \times 10^{4}$ was used in the BEMT.

\section{$3.3 \quad$ Failure analysis}

A composite material failure analysis based on Tsai-Hill failure theory [27] was implemented in the design tool to predict the likelihood of blade failure based on the composite design and operating conditions. The failure analysis used the longitudinal (parallel to the fibers), transverse (perpendicular to the fibers), and shear stresses in the composite blade computed by the FEM after each iteration. Safety factors were computed by taking the inverse of the Tsai-Hill failure index for each element in the composite FEM. These safety factors were used as an indication of the robustness of the composite design (higher safety factors indicating a more robust design and safety factors of less than one suggesting a high likelihood of failure). Details of the composite failure theory used, and the implementation in the design tool, are outlined in [31].

\section{RESULTS AND DISCUSSION}

\subsection{Experiment and design tool comparison}

Results of the towing tank tests were compared to the design tool predictions for the small-scale HATT. Figure 6 and Figure 7 show the rotor thrust at each carriage speed as a function of TSR, and Figure 8 and Figure 9 show the rotor torque at each carriage speed as a function of TSR, for the turbine with both composite and aluminum blades, compared to the design tool predictions. Figure 10 shows the difference in thrust between the composite and aluminum blades (units of $[\mathrm{N}]$ on left vertical axis, and \% on right vertical axis), with linear best-fit lines shown as well. The turbine performance with aluminum blades was predicted using the stand-alone BEMT (effectively modeling a turbine with rigid blades), and the turbine performance with composite blades was predicted using the design tool outlined in Section 3. Error bars are shown in these figures, with the experimental uncertainty discussed in Section 4.1.3.

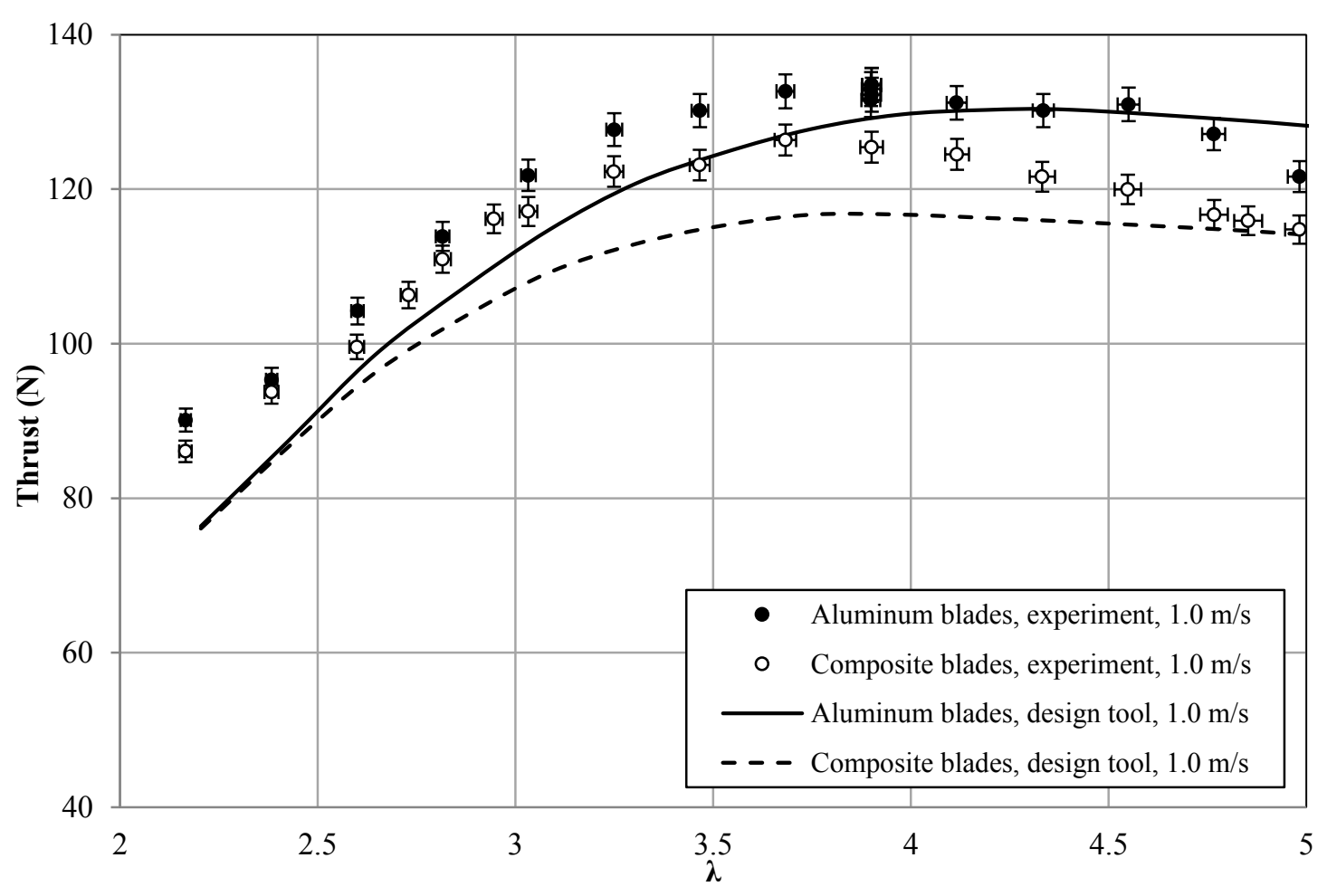


Figure 6 Rotor thrust of design tool compared to experiment for BT blades and rigid aluminum blades, carriage speed of $1.0 \mathrm{~m} / \mathrm{s}$.

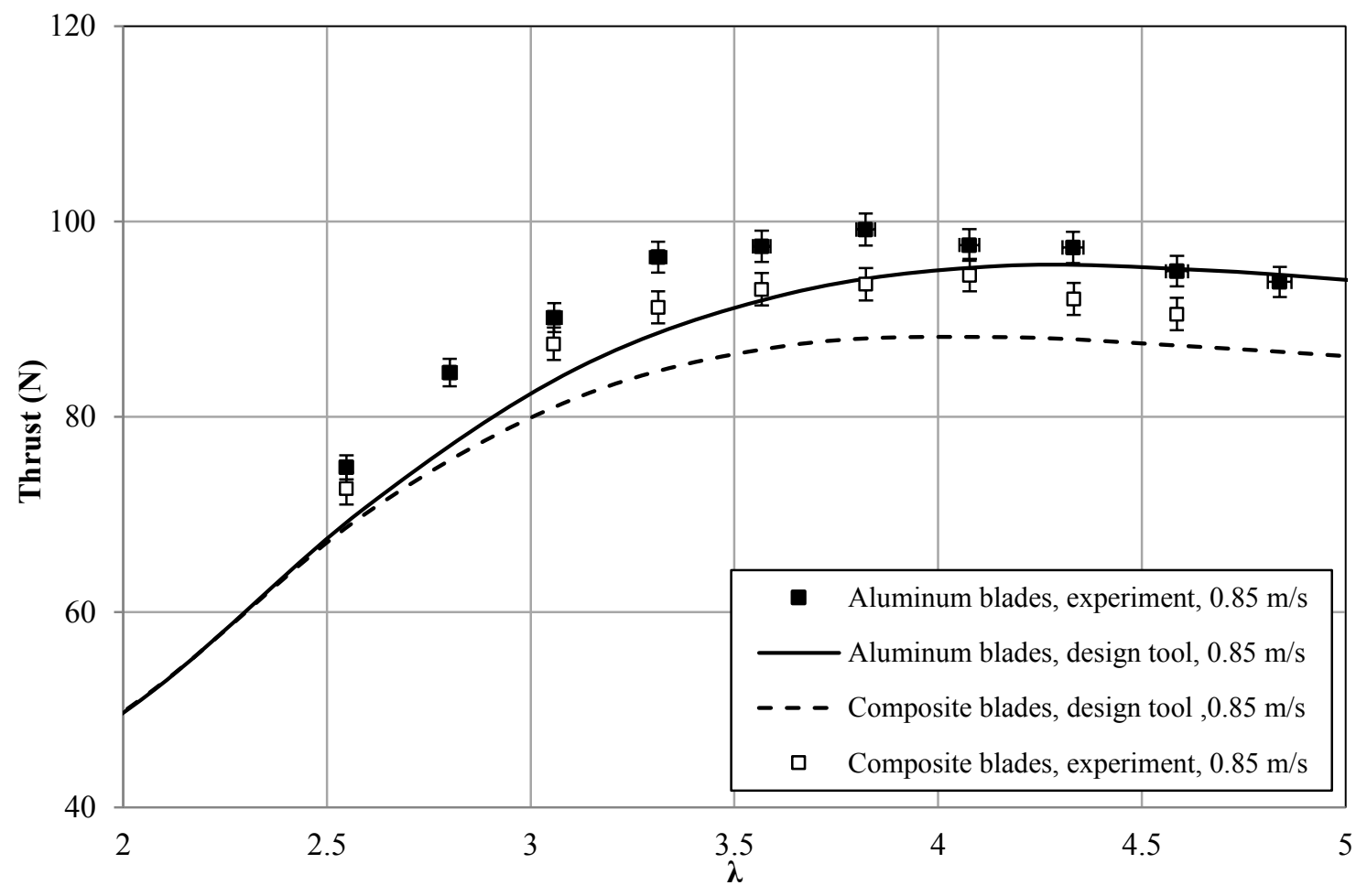

Figure 7 Rotor thrust of design tool and experiment for BT blades and rigid aluminum blades, carriage speed of $0.85 \mathrm{~m} / \mathrm{s}$.

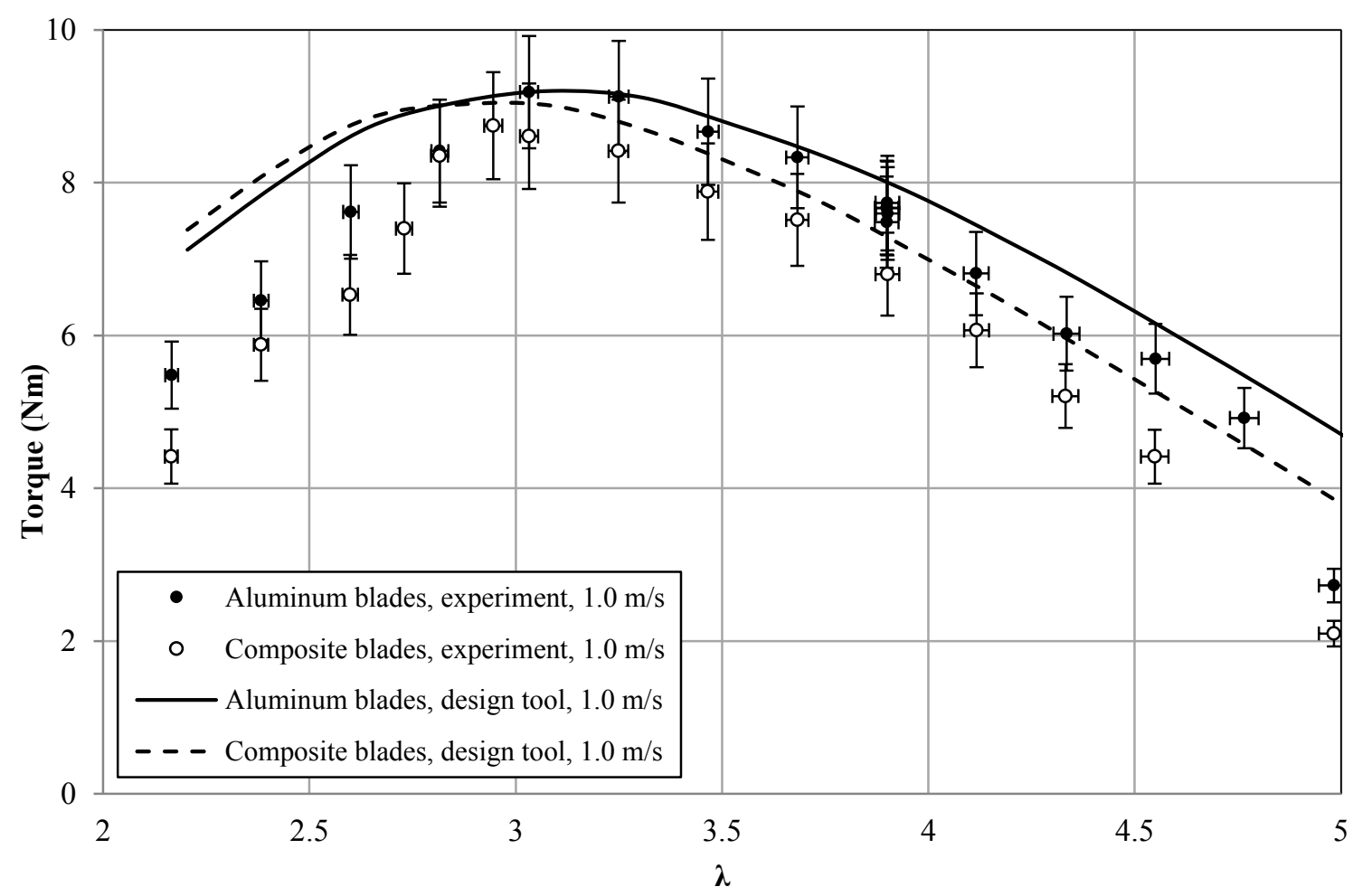

318 Figure 8 Rotor torque of design tool and experiment for BT blades and rigid aluminum blades, carriage speed of $1.0 \mathrm{~m} / \mathrm{s}$. 


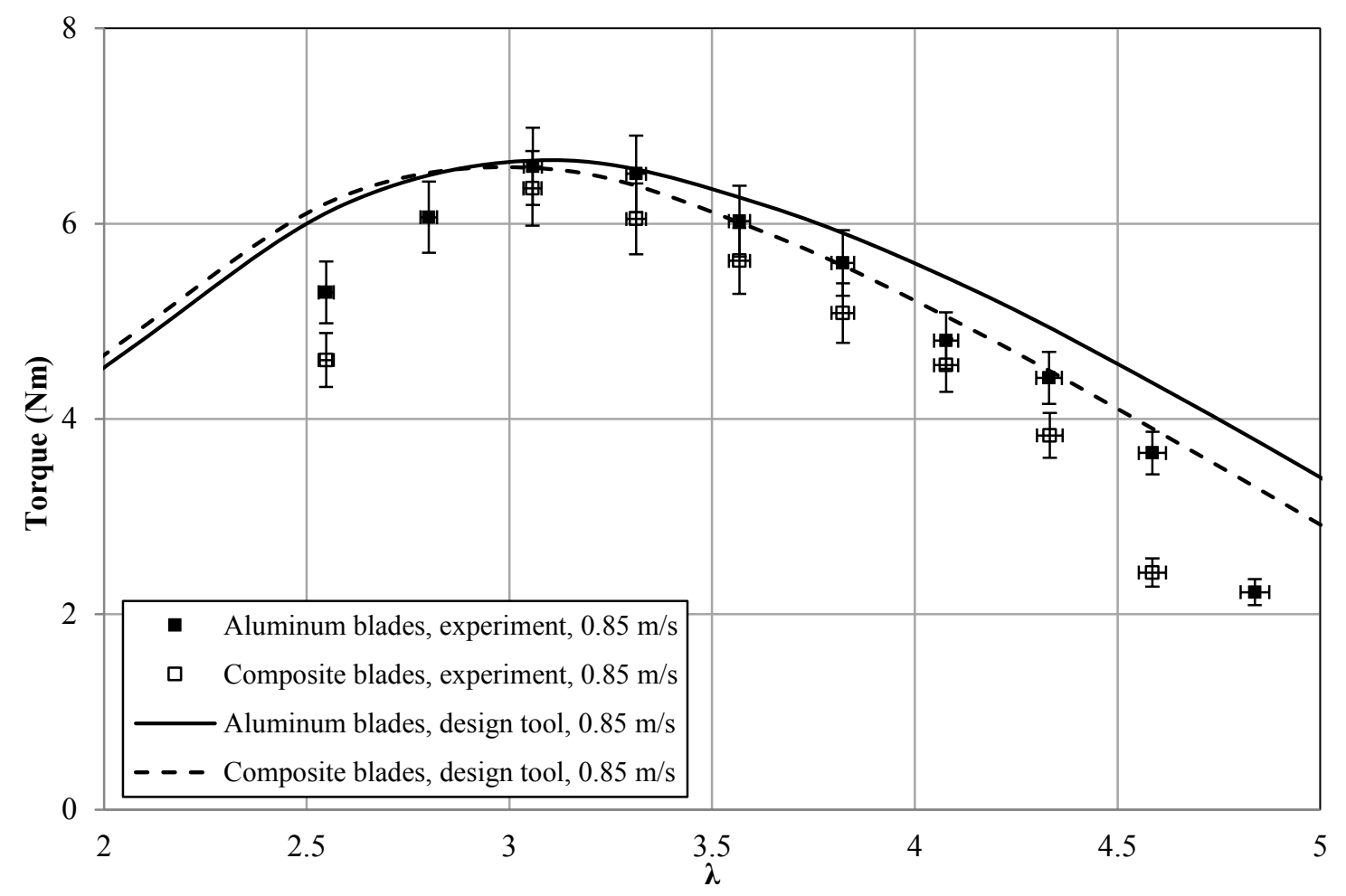

Figure 9 Rotor torque of design tool and experiment for BT blades and rigid aluminum blades, carriage speed of $0.85 \mathrm{~m} / \mathrm{s}$.

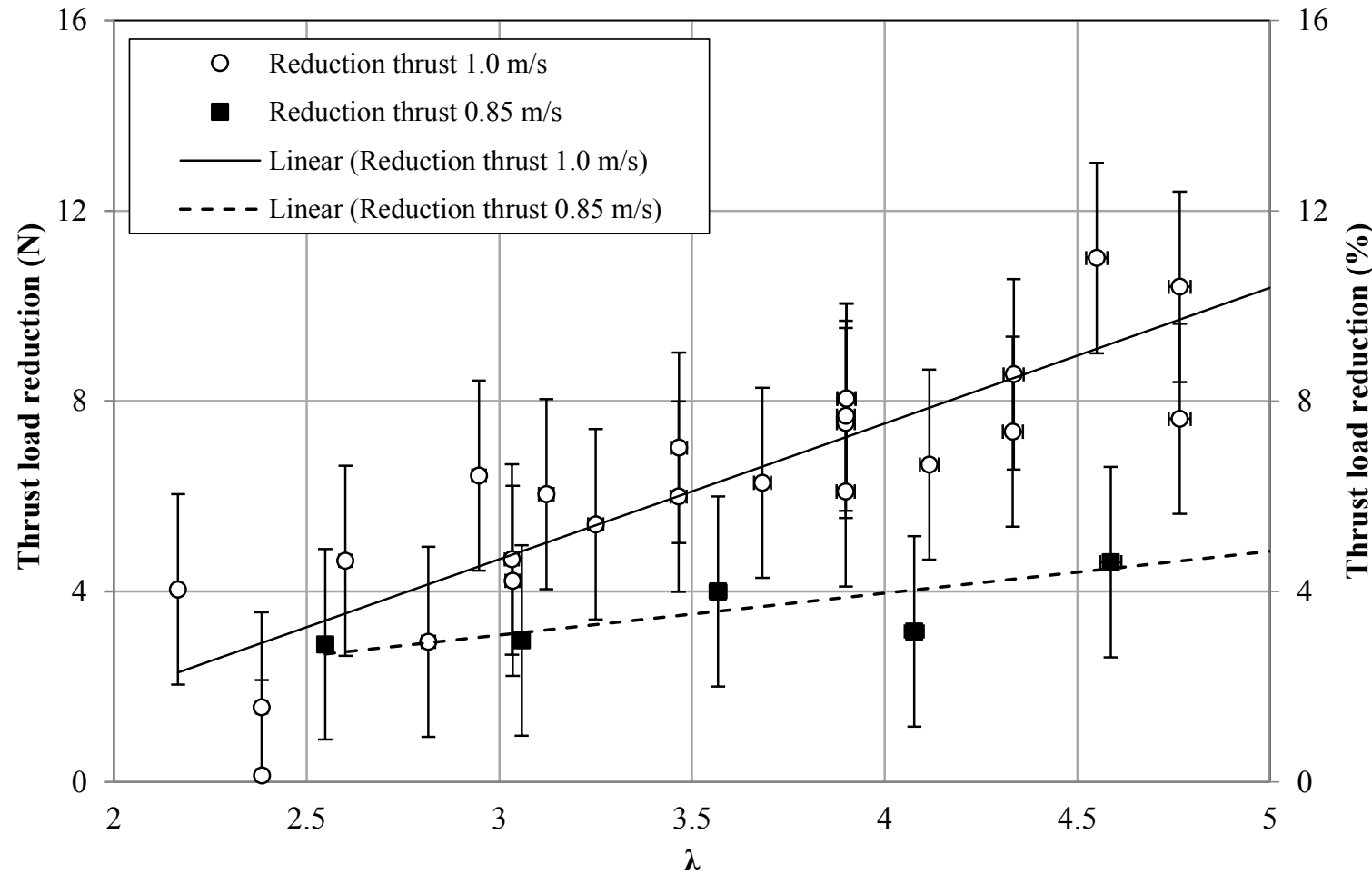

Figure 10 Reduction in thrust between the rigid and BT composite blades.

The difference between the performance of the turbine with composite and aluminum blades, evident in Figure 6 through Figure

10 , highlights the effect of BT coupling to reduce blade loads. The thrust load reductions associated with the BT composite blades 
was proportional to the magnitude of thrust on the rotor and increased with increasing flow speed and TSR. For example, the BT blades had up to $11 \%$ lower thrust loads at a flow speed of $1.0 \mathrm{~m} / \mathrm{s}$, and up to $4.6 \%$ lower thrust loads at a flow speed of $0.85 \mathrm{~m} / \mathrm{s}$, and both the $1.0 \mathrm{~m} / \mathrm{s}$ tests and the $0.85 \mathrm{~m} / \mathrm{s}$ tests had greater thrust reductions in the region of peak thrust. This is due to the higher blade loads causing the composite blades to increasingly twist toward feather, resulting in a greater difference in blade shape between the two sets. Increased twisting of the BT blades with increased loads was demonstrated previously by structural bending tests which showed the composite BT blades to have linearly increasing twist with applied load [31].

Similar to the thrust load reductions, the torque measured experimentally for the composite blades was reduced for all TSRs. This suggests that for flow speeds above the design conditions, the turbine power will be regulated, as desired. However, the reduced torque at low flow speeds means a decrease in the overall turbine power capture, which is not ideal. Additional investigations using the FEM-BEMT design tool indicated that keeping the composite design the same but altering the pre-twist blade geometry (designing an unloaded blade geometry that is more twisted toward stall), it is possible to achieve thrust and torque reductions above design conditions, while actually increasing the turbine power capture between cut-in and design speeds. More information on this method can be found in [31].

Figure 11 and Figure 12 show the percentage difference between the design tool and the experimental data for thrust and torque, respectively, for a carriage speed of $1.0 \mathrm{~m} / \mathrm{s}$.

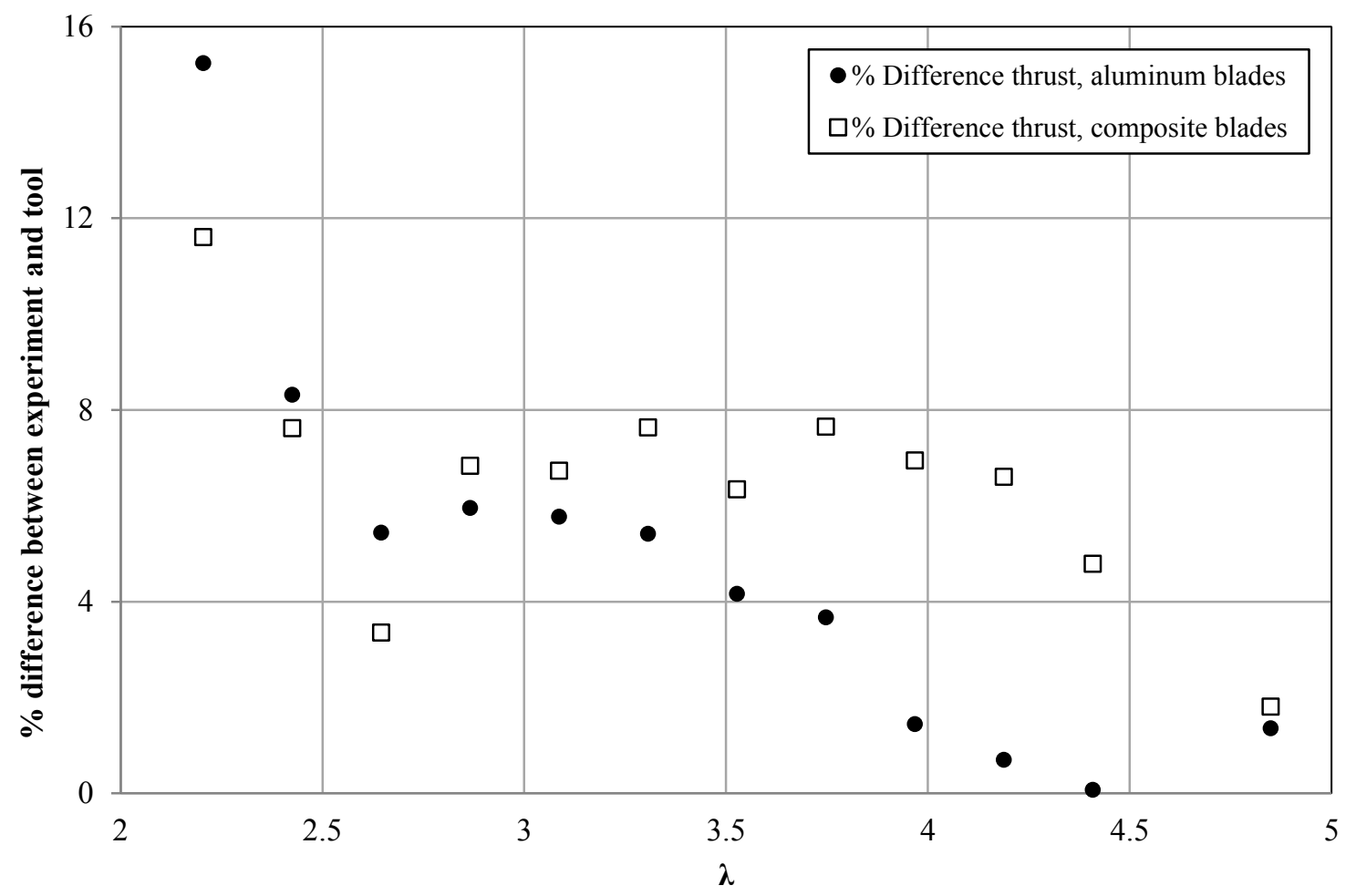

Figure 11 Percent difference in thrust between design tool predictions and experimental results, carriage speed of $1.0 \mathrm{~m} / \mathrm{s}$. 


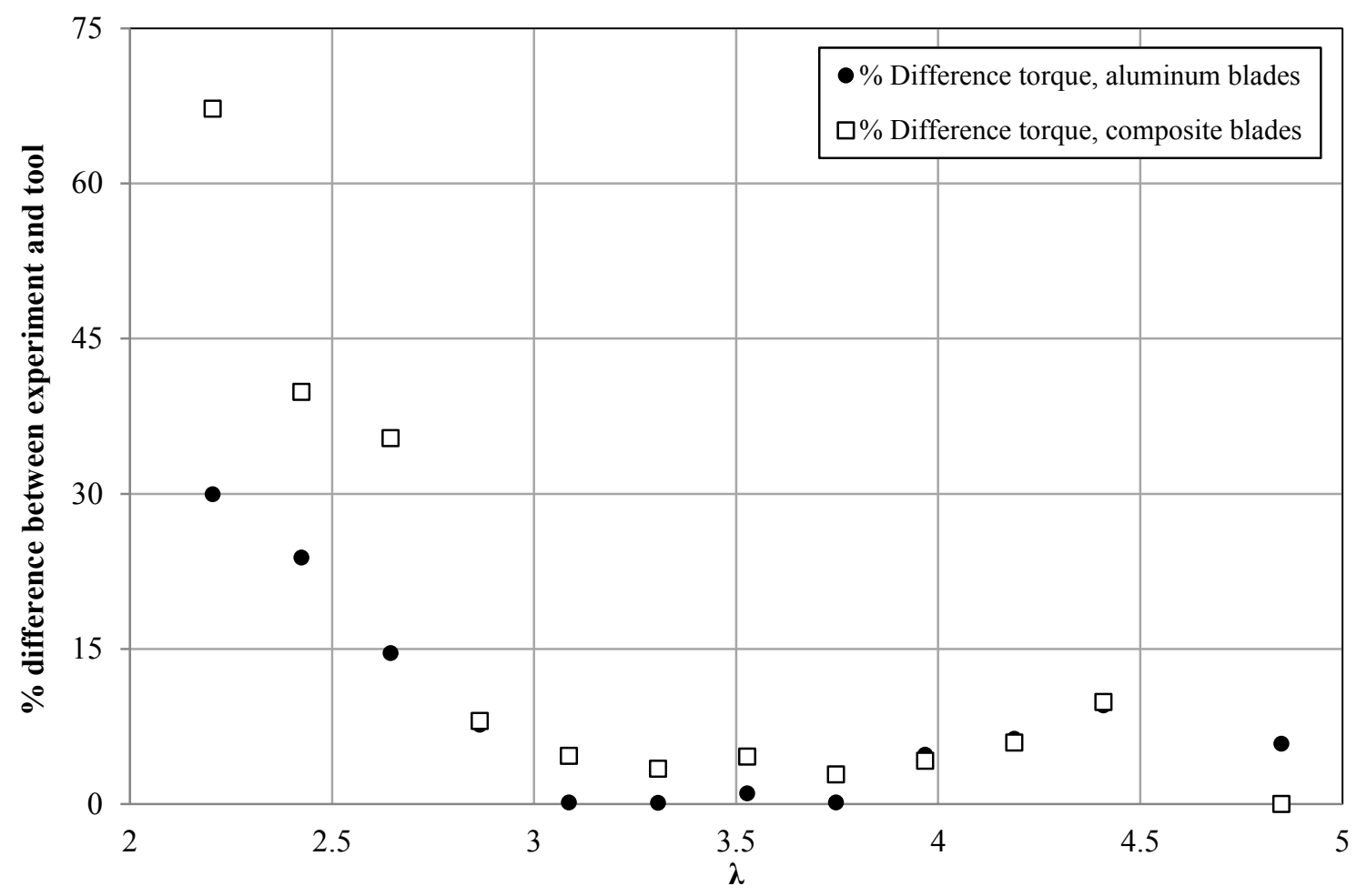

342

343

344

345

346

347

348

349

350

351

352

353

354

355

356

357

358

359

360

361

362

Figure 12 Percent difference in torque between design tool predictions and experimental results, carriage speed of $1.0 \mathrm{~m} / \mathrm{s}$.

With the exception of operating at low TSRs $(\lambda<2.5)$, the thrust was predicted by the design tool to within $6 \%$ for the rigid blades and $8 \%$ for the composite blades. For TSRs greater than 2.8 , the design tool predicted the experimental torque to within $10 \%$ for both blade sets. However, at low TSRs the design tool over-predicted the torque by up to $70 \%$ for the composite blades and $40 \%$ for the aluminum blades. As the BT blades twist along the blade span, the cross section is also deformed, causing the airfoil shape to differ from the theoretical NREL S814 airfoil. This slightly altered airfoil shape is not accounted for in the BEMT, which assumes the theoretical airfoil geometry and only considers the induced twist by the affect it has on the angle of attack. It is thought that this contributes to the greater discrepancy between the design tool and the turbine with composite blades.

The low torque measured experimentally at low TSRs indicates that there was performance degradation in the towing tank tests that was not accurately captured by the BEMT component of the design tool. For an airfoil operating in this range of Reynolds numbers (chord Reynolds numbers ranging from $8 \times 10^{4}$ to $1.7 \times 10^{5}$ based on a chord length of $0.047 \mathrm{~m}$ at $75 \%$ radius) the performance can be highly sensitive to the Reynolds number, with the performance degrading (increasing drag and decreasing lift) as the Reynolds number decreases [46]. Although the design tool captured the peak power and thrust reasonably well, the BEMT code does not account for this degraded airfoil performance as the Reynolds number decreases since airfoil data at a single Reynolds number was used. The discrepancy between the experiment and design tool at low TSRs could also be related to 3-D rotational effects that were not accounted for by the 2-D airfoil data. Such effects can be more pronounced at low TSR, but are not well quantified or understood for tidal turbines, and previous work has shown that 3D corrections in BEMT used for wind turbines do not work well for the tidal energy application [47].

The difference in the trailing edge geometry of the composite and aluminum blades compared to the theoretical NREL S814 airfoil shape (shown in Figure 3) is also an important consideration. To mitigate the effect of this trailing edge on the comparison 
between rigid blade and BT blade performance, the aluminum blades were machined to match the geometry of the composite blades. Although the blade geometry with this altered edge was used in the FEM, the BEMT component of the design tool is based on experimental airfoil data for the theoretical airfoil shape. This means that the airfoil modeled in BEMT did not take the altered trailing edge geometry into consideration. To investigate the significance of the trailing edge differences, XFOIL was used to estimate lift and drag coefficients for both the 2-D theoretical and altered airfoil shapes. The altered airfoil shape was input to XFOIL using the 2-D CMM scan data normalized by the chord length. Because XFOIL did not converge at the Reynolds numbers of the tests, Reynolds numbers of $1 \times 10^{6}, 2 \times 10^{6}$, and $5 \times 10^{5}$, and an NCRIT value of 2 were used. On average there was less than $2.6 \%$ difference in lift and less than $2.1 \%$ difference in drag between these two airfoil shapes for angles of attack greater than $5^{\circ}$. This difference in airfoil performance is within the uncertainty for the experiment and hence is not expected to have a significant contribution to the mismatch of the design tool. These XFOIL predictions give a relative estimate of the sensitivity of the airfoil to the trailing edge alteration at higher Reynolds numbers, however, a more in-depth investigation is recommended to compare these airfoil shapes at the low Reynolds numbers that were tested.

Figure 13 shows an image of the composite blades for test conditions of 100 RPM and $1 \mathrm{~m} / \mathrm{s}$ taken from a video recorded using a 1920x1080 pixel (FHD) video camera.
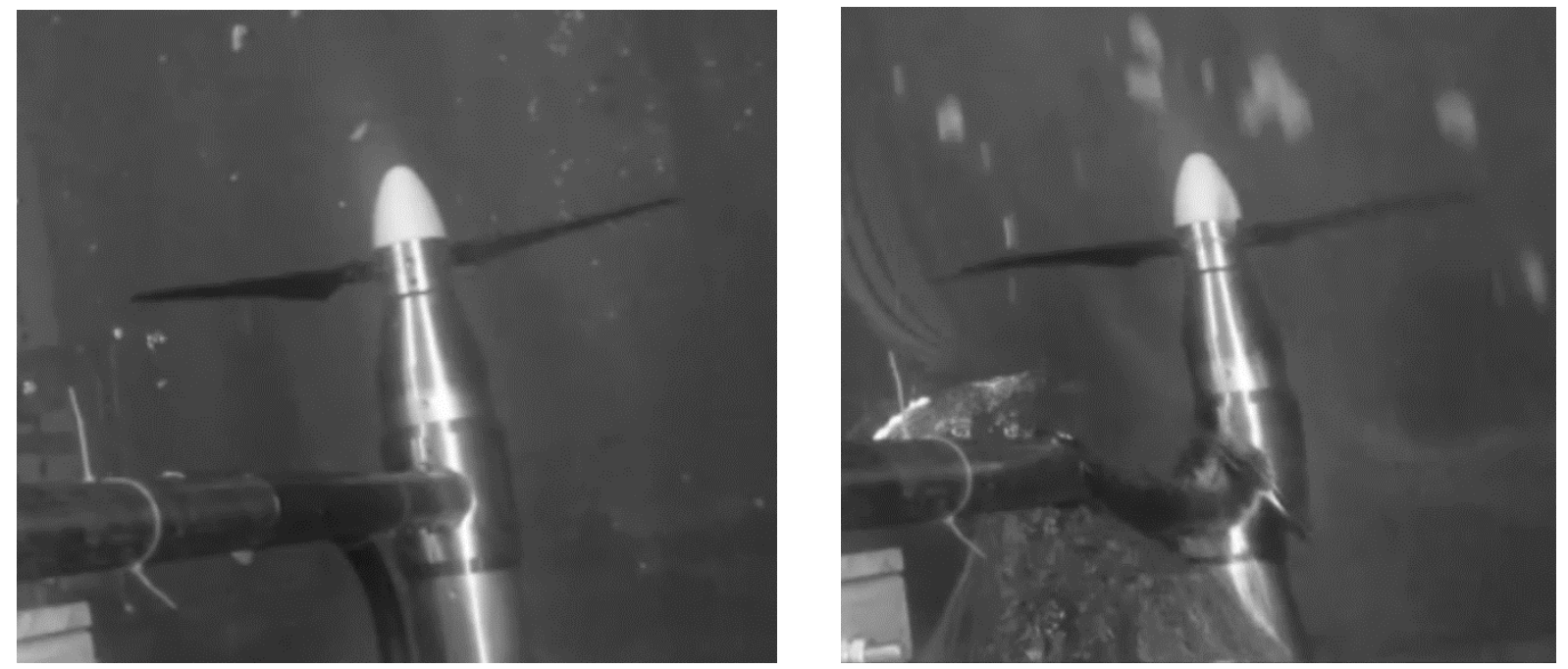

Figure 13 Left) Composite blades prior to carriage ramping up (unloaded) Right) Composite blades at a carriage speed of 1 $\mathrm{m} / \mathrm{s}$ and rotational speed of $100 \mathrm{RPM}$ (loaded).

The BT blades at these conditions were predicted by the design tool to have up to $8.7 \mathrm{~mm}$ of bending displacement and $1.8^{\circ}$ of tip twist. The image on the left in Figure 13 shows the blades unloaded and the image on the right shows the blades once the carriage speed and rotational speed were steady (loaded). From the image on the right, the blades appeared to bend under load. Although the BT blade deformation was not quantified during towing tank testing, the observed bending and the relative difference in thrust and torque between the composite blades and the rigid blades suggests that the BT blades were twisting to feather as expected.

Although most HATT blades are now being made of composite materials, the comparison to rigid blades is valuable. The difference in load trends between the turbine with rigid aluminum blades and more flexible composite blades highlights the importance of considering the coupling of structural deformation with hydrodynamic performance (fluid-structure interaction, FSI) in numerical design tools. In this case, modelling the turbine with BT blades without the consideration of the blade 
deformation (using the stand-alone BEMT code without coupling to FEM) would have resulted in an $11 \%$ over-estimate in the blade loads, which has implications on the sizing of other turbine components.

\subsubsection{Uncertainty analysis}

EquiMar deliverable 3.4 [48] and the International Towing Tank Conference protocol [49] give guidelines for performing uncertainty analysis and propagating error in experimental results. This section briefly outlines the method used to estimate the experimental uncertainty given in the error bars in Figure 6 to Figure 10. More detail on the uncertainty analysis method can be found in [25].

The total uncertainty in a measurement is a combination of the precision uncertainty and the bias uncertainty. A precision uncertainty is associated with the fact that when a measurement is repeated it will generally provide a measured value that is different from the previous value. For a linear regression analysis (used for equipment calibration), this is given by the standard error of estimate, which is a measure of the accuracy of predictions made with a regression line [50]. A bias error is based on the fact that a measured value contains an offset and is defined as the portion of the total measurement error that remains constant in repeat measurements of a quantity (usually based on relevant information such as measurement equipment limitations, manufacturer's specifications, data provided from other sources, etc.). The total combined uncertainty associated with a measurement is given by taking the square root of the sum of the precision and bias uncertainties squared.

An expanded uncertainty qualifies the combined uncertainty by including a coverage factor (an interval around the measurement that has a specific probability of containing the true value) and is included in the final calculated uncertainty by multiplying the combined uncertainty by a coverage factor. Lastly, the law of propagation of uncertainty is used to estimate the combined effect of uncertainty from different measurement sources into a calculated quantity, for example, for estimating the uncertainty in the TSR.

The precision, bias, and combined expanded uncertainty values for the measured thrust, torque, carriage speed, rotational speed, and TSR, are given in Table 3 for one example test case. A similar analysis was done for all tests. The bias uncertainty in the turbine radius used to estimate the TSR uncertainty is discussed in Section 2.1, and the bias uncertainty in the torque measurement was not available at this time. The precision uncertainty given in Table 3 is based on the standard deviation of six tests repeated at $1.0 \mathrm{~m} / \mathrm{s}$ and $90 \mathrm{RPM}$. The combined expanded uncertainty was calculated using a coverage factor of 2.2, and is given in Table 3 as a percentage of the mean values to demonstrate the relative magnitude of uncertainty in each of the parameters presented.

Table 3: Precision, bias and combined expanded uncertainty values for measurements for one test case.

\begin{tabular}{l|ccccc}
\hline Uncertainty values & $\begin{array}{c}\text { Mean } \\
\text { value }\end{array}$ & $\begin{array}{c}\text { Precision } \\
\text { uncertainty }\end{array}$ & $\begin{array}{c}\text { Bias } \\
\text { uncertainty }\end{array}$ & $\begin{array}{c}\text { Combined } \\
\text { expanded } \\
\text { uncertainty }\end{array}$ & $\begin{array}{c}\text { Combined expanded } \\
\text { as a percentage of } \\
\text { mean value (\%) }\end{array}$ \\
\hline Torque (Nm) & 8.49 & 0.21 & N/A & 0.42 & 4.9 \\
Thrust (N) & 125.12 & 0.83 & 0.045 & 1.65 & 1.32 \\
Rotational speed (RPM) & 90.22 & 0.12 & 0.20 & 0.48 & 0.53 \\
Flow velocity (m/s) & 1.01 & 0.00053 & 0.0010 & 0.0023 & 0.23 \\
$\lambda$ & 3.97 & 0.00205 & N/A & 0.0041 & 0.11 \\
\hline
\end{tabular}

The combined expanded uncertainty in the thrust as a percentage of the mean was less than $2 \%$ for all the tests done. This was 
gauge calibration. The combined expanded uncertainty in the torque as a percentage of the mean was less than 5\% for the majority of the tests done, but increased to over $6 \%$ for TSRs greater than 4.5 . This was a result of the relatively large precision uncertainty in the torque measurement due to scatter in the repeat tests which is thought to be due to the calculation of the rotor torque from the TGC, but is being investigated further. The higher uncertainty in the torque measurement compared to the thrust is evident by the size of the error bars in Figure 6 to Figure 9. The uncertainty in the TSR, also evident in the error bars in Figure 6 to Figure 9 , was based on the uncertainty in the flow speed, rotational speed, and turbine radius, and was less than $1 \%$ for all tests. The magnitude of the error bars in the thrust plots relative to the difference between the thrust loads for the two blade sets verifies that the experimental setup was sufficiently sensitive to measure these thrust load differences. The error bars in Figure 10 are large due to the relative difference between the composite and aluminum blade thrust measurements (less than $10 \mathrm{~N}$ ) compared to the combined expanded uncertainty in the thrust measurement, which was $\pm 1.65 \mathrm{~N}$.

\subsection{Transient experiemntal results}

The tests presented in this paper were performed under steady flow conditions, however, this section investigates the transient nature of the loads on the composite and aluminum blades. Figure 14 shows the transient thrust signal for tests conducted at 80 $\mathrm{RPM}$ and $1.0 \mathrm{~m} / \mathrm{s}(\lambda=3.53)$ over a 5 second period, and Figure 15 shows the frequency domain plot for both the composite and aluminum blades. In Figure 14, the thrust was normalized by the mean value for each blade set and the signals were aligned so that the blades were in the same rotational positions at time zero.

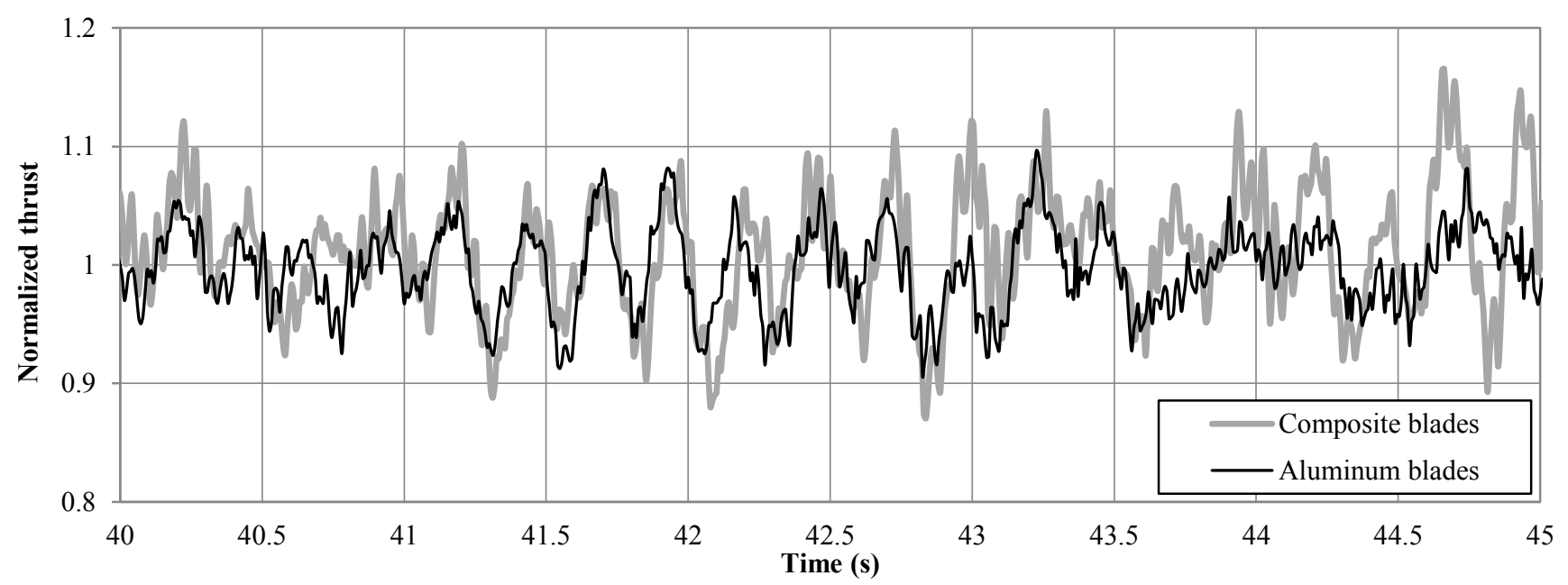

Figure 14 Transient thrust signal for a rotational speed of $80 \mathrm{RPM}$ and carriage speed of $1.0 \mathrm{~m} / \mathrm{s}(\lambda=3.53)$ for the composite and aluminum blades. 


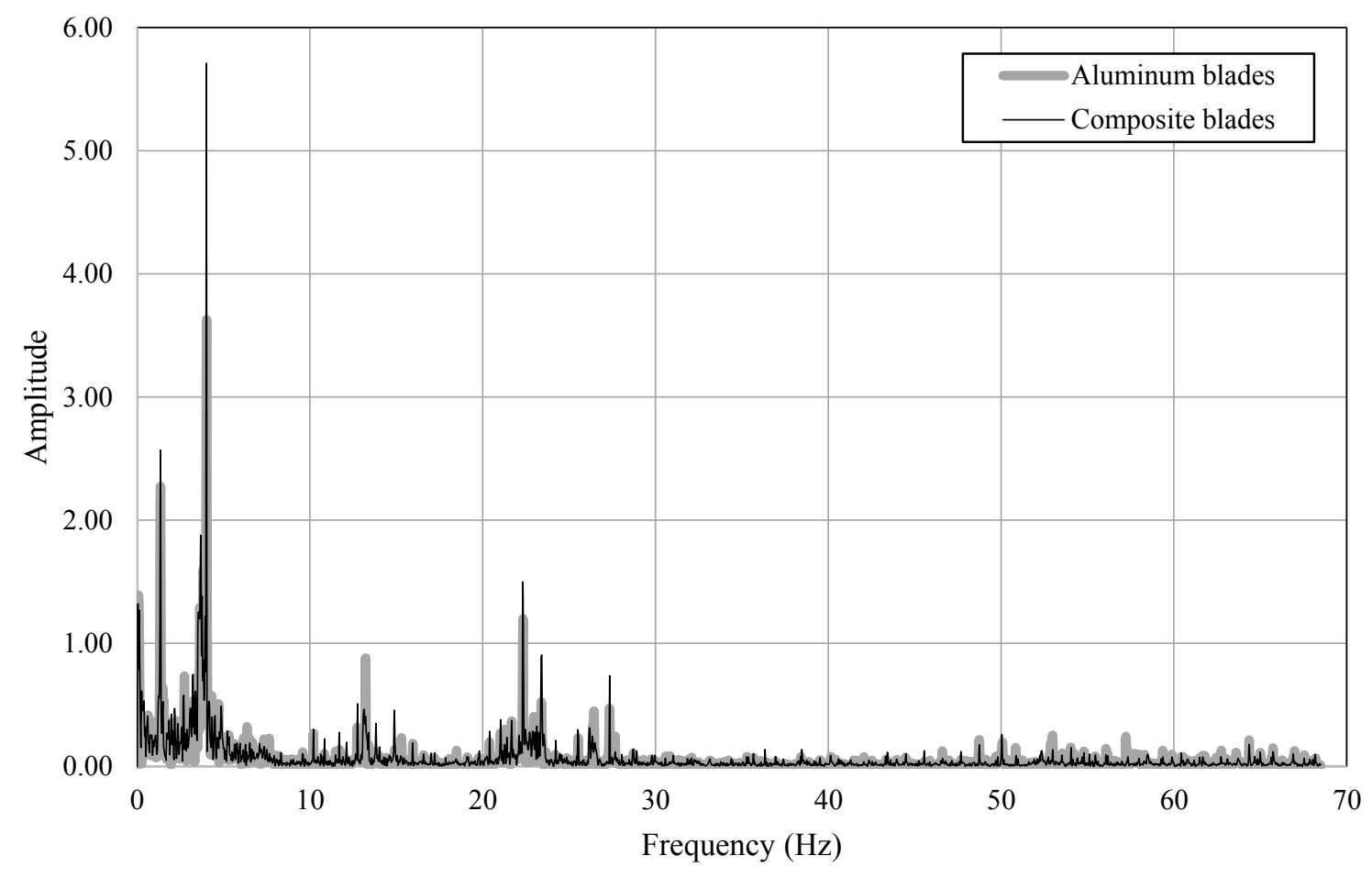

Figure 15 Frequency domain of thrust signal for a rotational speed of 80 RPM and carriage speed of $1.0 \mathrm{~m} / \mathrm{s}(\lambda=3.53)$ for the composite and aluminum blades.

A spectral analysis using a fast Fourier transform was performed on the thrust signals shown in Figure 14. Both blade sets had well correlated frequency responses, showing similar dominant frequencies. The primary sources of the turbine thrust variations observed in Figure 14 were gravitational (occurring at the rotational frequency of the turbine, $1.33 \mathrm{~Hz}$ ) and blades passing the stanchion (occurring 3 times per rotor revolution, $4 \mathrm{~Hz}$ ). The presence of the stanchion causes a reduction in the flow speed in front of the turbine so that the blades experience reduced flow, which results in a variation in the loads on a blade in the top vertical position. This blade passing frequency corresponds with the most significant load fluctuations evident in Figure 14. The higher frequency peaks around $13 \mathrm{~Hz}$ and $22 \mathrm{~Hz}$ coincide with the natural frequency of the support system, which was obtained from a vibration impact test performed by impacting the stanchion and observing the response while the system was at rest. A spectral analysis was done for the torque signal as well, which showed similar dominant frequencies.

Although the mean rotor thrust was lower for the turbine with composite BT blades, the thrust load fluctuations were approximately $5.4 \%$ for the composite blades compared to $4.7 \%$ for the aluminum blades. For these tests the rotor thrust was measured by a strain gauge on the turbine stanchion, hence these results give the load fluctuations on the stanchion due to the hydrodynamic forces acting on the blades. This indicates that cyclic gravitational effects and blades passing the stanchion resulted in slightly increased stanchion vibratory loads with the more flexible BT blades. Compared to thrust load variations arising due to unsteady loads from turbulence or waves, the fluctuating loads observed in these tests are thought to be relatively insignificant. For example, Milne et al. [51] showed that a turbine experiencing dynamic stall due to unsteady loads could have $25 \%$ greater loads than at steady flow conditions, and Galloway et al. [52] showed that cyclic load fluctuations due to waves could be up to $37 \%$ of the mean load. As well, Tatum et al. [53] showed that the natural fluctuations due to blade rotations were small compared 
to the extreme load fluctuations due to waves, which can increase blade loads by $34 \%$. The next stages of this work will investigate the significance of load fluctuations in steady flow conditions compared to fluctuating loads arising from waves and turbulence.

\subsection{Stress analysis}

Using the FEM-BEMT design tool, the stresses in the composite blade and the likelihood of blade failure as a function of the turbine operating conditions were estimated. Figure 16 shows the Tsai-Hill failure index (inverse of the Tsai-Hill SF), the $y$ displacement of the blade, and the tensile normal stresses in the longitudinal fiber direction, at conditions of $1.0 \mathrm{~m} / \mathrm{s}$ and $80 \mathrm{RPM}$.
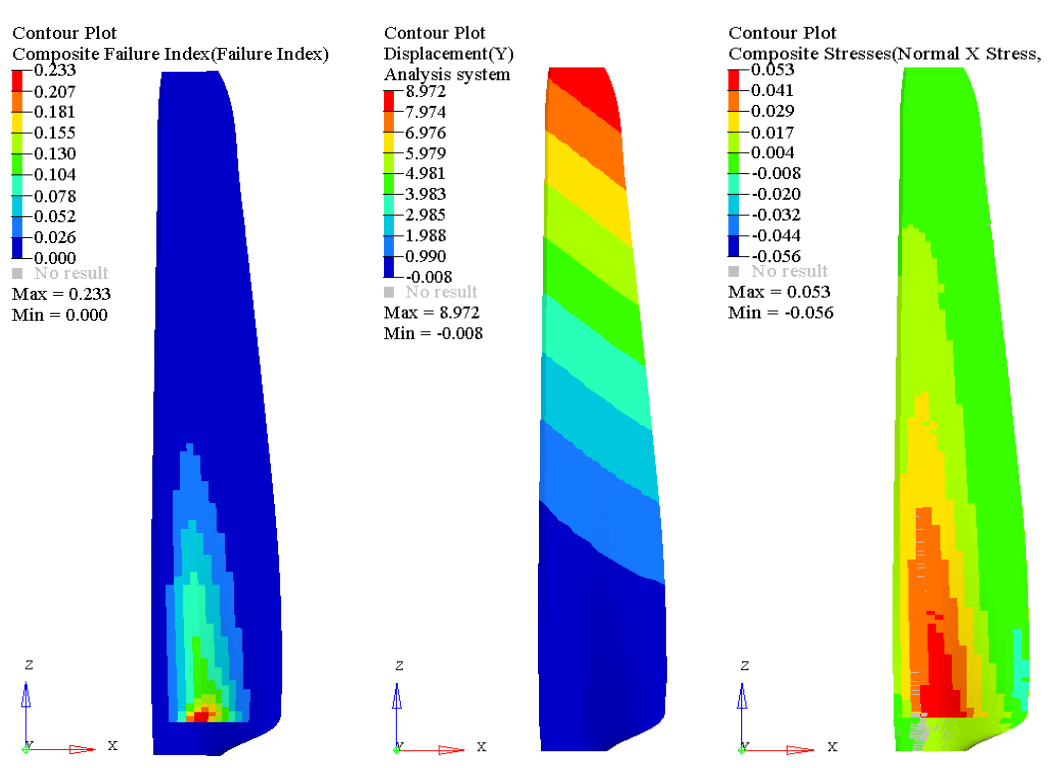

Figure 16 FEM composite blade contour plots after convergence for a $1.0 \mathrm{~m} / \mathrm{s}$ and 80 RPM design case ( $\lambda=3.53)$, left) Tsai-Hill failure index, middle) $y$-displacement (mm), right) normal stress in 1-direction ( $\mathrm{GPa})$.

From the displacement contour plot, the trailing edge of the blade has greater $y$-direction bending than the leading edge, indicating twisting to feather at the outer span of the blade. From the contour stress plots and failure indices, the highest stresses in the composite material occurred at the blade root, where a ply drop (distinct change in composite thickness) caused a stress concentration. From Figure 16, at these conditions the Tsai-Hill failure index was 0.233 , giving a safety factor of 4.29 , indicating a low likelihood of failure. Other literature reports using safety factors for blade design between 1.3 [2] and 1.6 [12], therefore a safety factor above 4 is conservative. It should be noted that a high safety factor was used in this case given the one-off nature of the blade manufacturing and the risk associated with testing BT blades in the towing tank for the first time.

Figure 17 shows the composite safety factors based on Tsai-Hill failure theory and the tip twist predicted by the design tool as a function of TSR. 


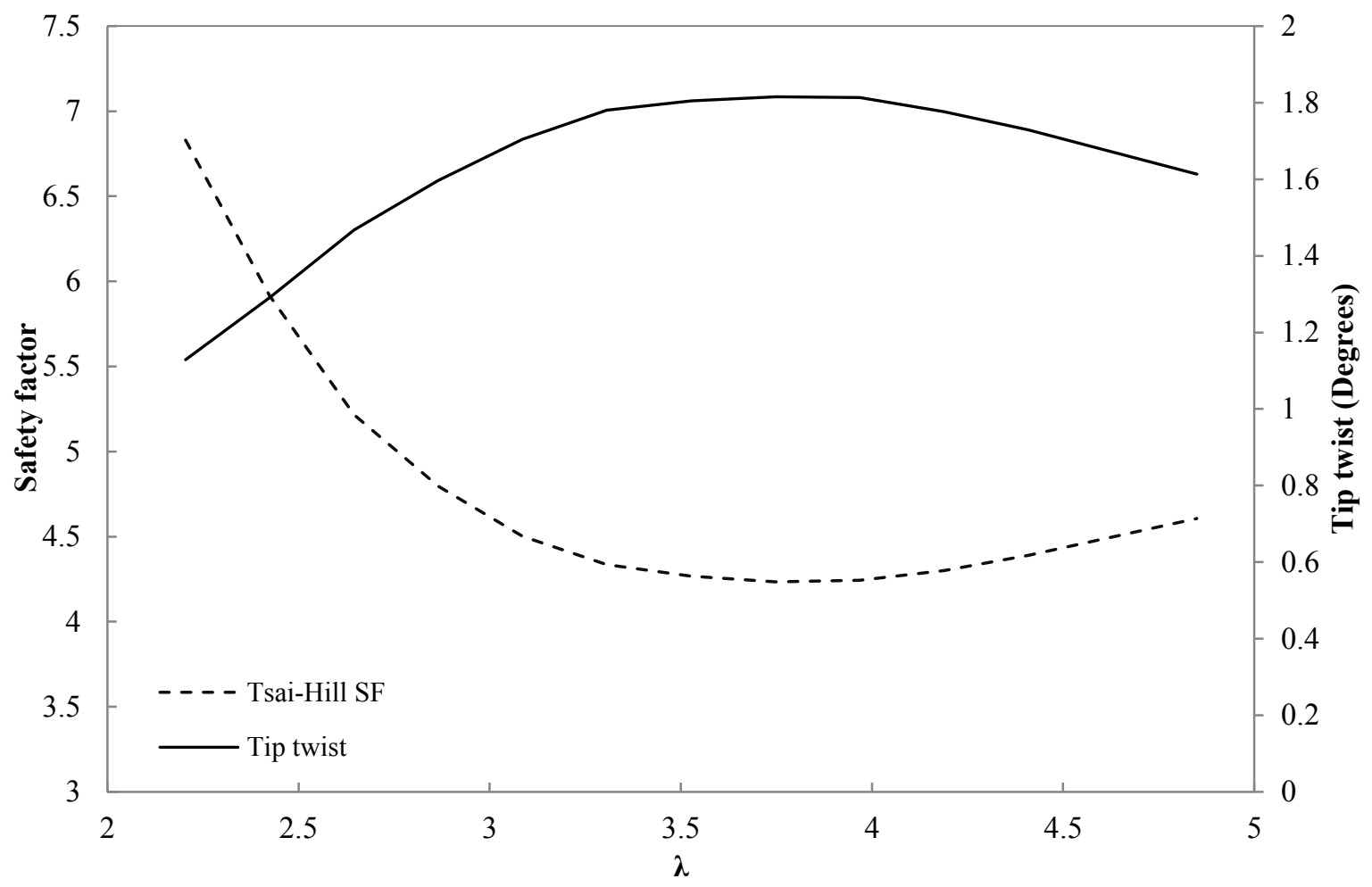

Figure 17 Safety factors for composite blade based on FEM predicted stresses.

Based on Tsai-Hill failure theory, the design tool predicted safety factors that decreased as the blade twist increased. In this simulation, a minimum safety factor of 4.23 and maximum twist of $1.81^{\circ}$ occurred at $\lambda=3.8$, which coincides with the peak thrust shown in Figure 6. From previous work, as the blade twists, the transverse tensile and shear stresses increase [31]. Tsai-Hill failure theory considers the interaction of stresses in different material directions, hence, the safety factor based on this failure theory decreases when the amount of blade twist increases. This simulation took less than 10 minutes to converge over the range of TSRs, in TSR increments of 0.25 , on a standard engineering workstation, making this a fast and efficient design tool for the simulation of this turbine.

\subsection{Sensitivity analysis}

Turbine performance predictions were found to have varying degrees of sensitivity to the input data used in the design tool. To explore the sensitivity of the BEMT component of the design tool to the input airfoil data, the Togneri et al. [45] airfoil data was used as a base-case and the lift and drag coefficients were altered. For this sensitivity study, only the aluminum blades were considered, as only the BEMT component of the design tool was used. To investigate the coupled effect of altering lift and drag coefficients to mimic airfoil degradation and enhancement, four cases were trialed, given in Table 4. A similar investigation was done by Masters et al. [54], in which they sequentially altered the lift and drag coefficients from a base case. Masters et al. studied the effects of significant performance degradation due to factors such as biofouling or surface pitting due to cavitation by using cases with decreased lift ( $C_{\mathrm{L}}$ decreased by $10 \%$ at all inflow angles) and increased drag $\left(C_{\mathrm{D}}\right.$ increased by $50 \%$ at all inflow angles). They stated that these alterations in airfoil data were in line with those found in other investigations, therefore, similar alterations were made for this study. Figure 18 and Figure 19 show the variations in thrust and torque based on the four cases.

Table 4: Modifications in lift and drag data for sensitivity investigation.

\begin{tabular}{l|llll}
\hline Case & Lift & Drag & Reason & Outcome
\end{tabular}




\begin{tabular}{|c|c|c|c|c|}
\hline A & $\begin{array}{l}10 \% \\
\text { decrease }\end{array}$ & $\begin{array}{l}50 \% \\
\text { increase }\end{array}$ & $\begin{array}{l}\text { Mimic airfoil performance } \\
\text { degradation }\end{array}$ & $\begin{array}{l}\text { Under predicts thrust and torque at } \lambda>3 \text {, but better } \\
\text { match to torque at } \lambda<3\end{array}$ \\
\hline B & $\begin{array}{l}5 \% \\
\text { decrease }\end{array}$ & $\begin{array}{l}25 \% \\
\text { increase }\end{array}$ & & Under predicts thrust and torque at $\lambda>3$ \\
\hline $\mathrm{C}$ & $\begin{array}{l}5 \% \\
\text { increase }\end{array}$ & $\begin{array}{l}25 \% \\
\text { decrease }\end{array}$ & $\begin{array}{l}\text { Mimic airfoil performance } \\
\text { improvement }\end{array}$ & $\begin{array}{l}\text { Better match to experimental thrust, but over- } \\
\text { predicts torque }\end{array}$ \\
\hline D & $\begin{array}{l}10 \% \\
\text { increase }\end{array}$ & $\begin{array}{l}50 \% \\
\text { decrease }\end{array}$ & & $\begin{array}{l}\text { Better match to experimental thrust, but over- } \\
\text { predicts torque }\end{array}$ \\
\hline
\end{tabular}

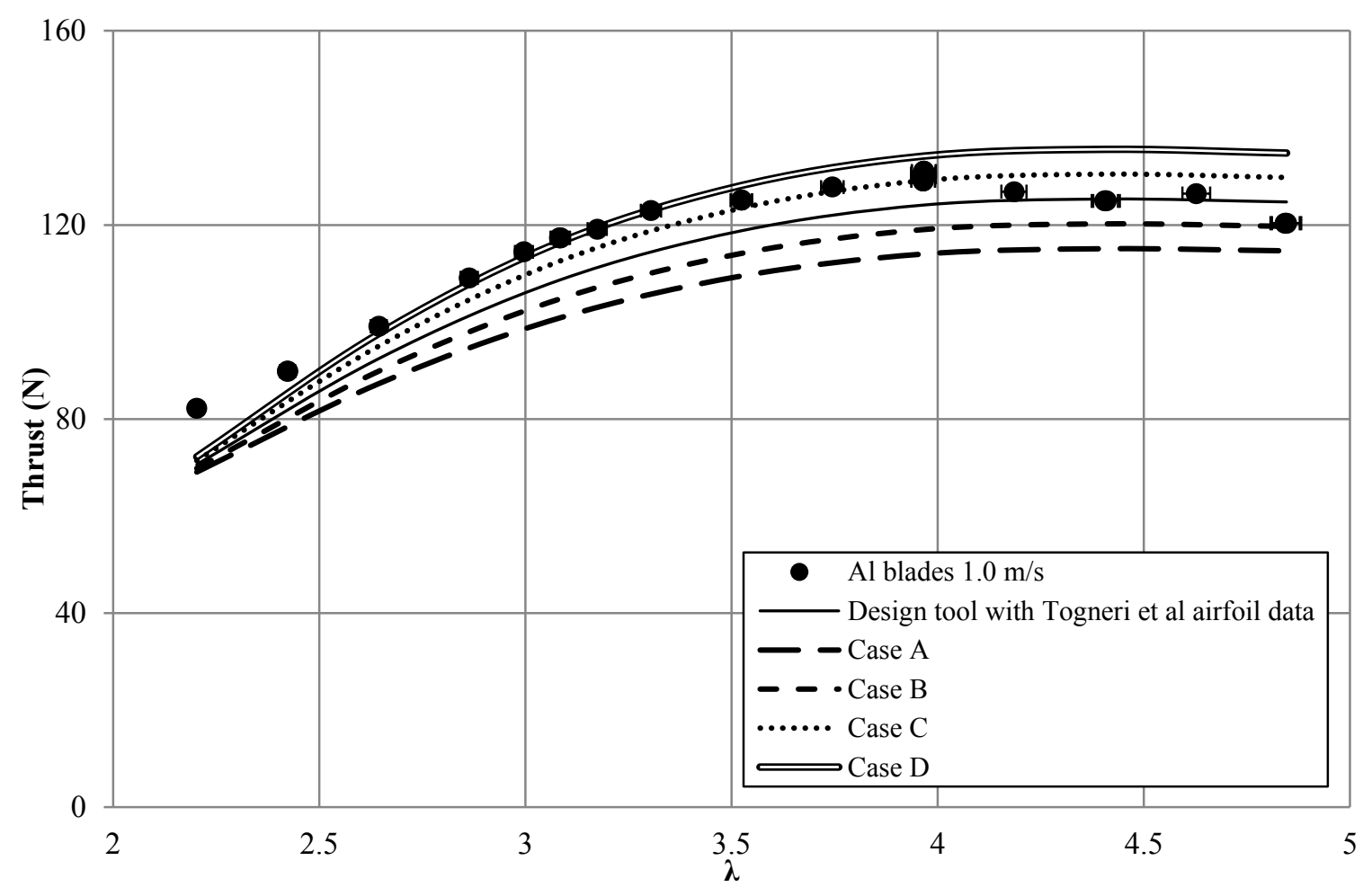

Figure 18 Thrust- $\lambda$ as a function of varying lift and drag, from the Togneri et al. base-case. 


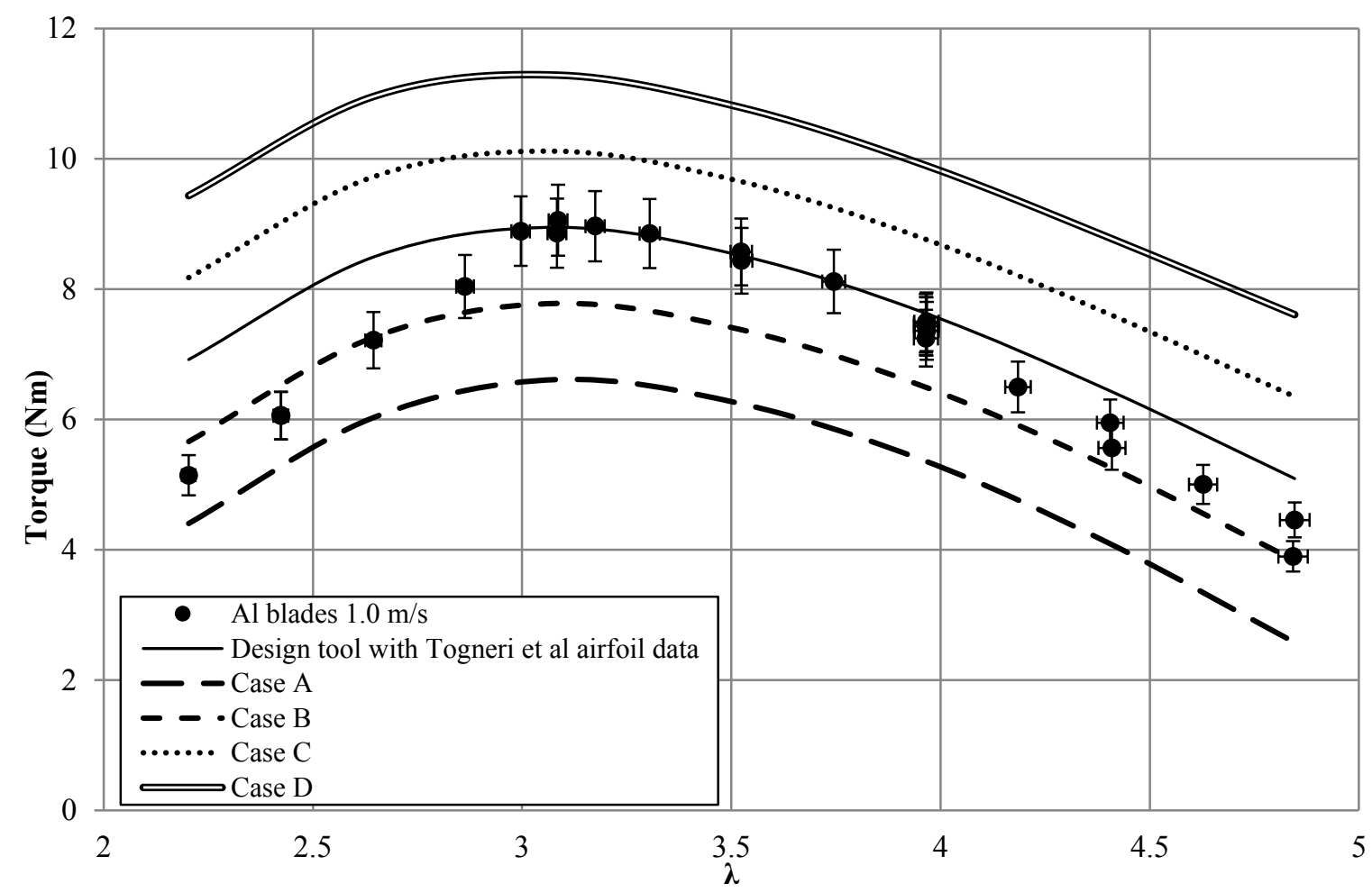

Figure 19 Torque- $\lambda$ as a function of varying lift and drag, from the Togneri et al. base-case.

502

503

504

505

506

507

508

509

510

511

512

513

514

515

516

517

518

519

520

521

The rotor torque was highly sensitive to simultaneous variations in lift and drag. Case D (improved airfoil performance) had $27.8 \%$ higher torque predicted by BEMT than the baseline airfoil data, whereas thrust was only effected by $8.5 \%$ at the most. This is likely due to the thrust being more sensitive to lift, which was only altered by $10 \%$ compared to the $50 \%$ alteration in drag. With the degraded airfoil performance (Case A), the predicted torque was reduced by $25.4 \%$, which would have major implications on the overall power capacity of the turbine.

Interestingly, an improvement in the airfoil performance (higher lift and lower drag, Case C and D), resulted in a better match to the thrust experimental data, but greatly over-predicted the torque at low TSR. In order to better match the torque data at low TSR, a degraded airfoil performance (increased drag and lower lift, Case A) was required. This is in agreement with the airfoil performance degradation expected at low TSRs due to low Reynolds number operation. However, the degraded airfoil performance (Case A) did not fit the experimental thrust data at low TSR. These observations highlight the sensitivity of the BEMT predictions to airfoil performance, and require further investigation into the potential reasons for this sensitivity.

Compared to the influence of the airfoil data, the sensitivity of the design tool to the turbine geometrical parameters was minor. $\mathrm{A} \pm 0.5^{\circ}$ change in pitch setting angle (a greater variation than the uncertainty in this parameter, which was estimated at $\pm 0.38^{\circ}$ ) resulted in less than a 3\% change in the thrust and torque predictions. This is small compared to the roughly $11 \%$ reduction in thrust loads associated with the $1.8^{\circ}$ of tip twist predicted by the design tool based on BT coupling. It was also found that $\pm 5 \%$ changes in the composite ply angles and skin thickness had less than a $1 \%$ effect on the composite blade global performance. This indicates a lower sensitivity of the design tool to the composite FEM inputs compared to the sensitivity to the BEMT inputs, highlighting the stability of the FEM component of the design tool. 
A tidal turbine with BT composite blades and geometrically equivalent aluminum blades was tested in the towing tank at the University of Strathclyde, with experimental results compared to an FSI design tool. The following outlines the main conclusions and future work based on the research reported herein:

- Towing tank testing of an $828 \mathrm{~mm}$ diameter tidal turbine showed composite BT blades to have up to $11 \%$ lower thrust loads than geometrically equivalent aluminum blades when comparing the mean thrust for each test. Reduced structural loads using BT composite blades means that smaller, less expensive turbine components can be used, increasing the cost effectiveness of the HATT.

- Test results showed a turbine with BT blades has reduced rotor torque for all TSRs. This will reduce loads on the generator above rated power, however, between cut-in and design flow speeds the overall power capture of the turbine will be reduced. Future designs will consider pre-twisted blade geometries to optimize power capture between cut-in and design speeds while still reducing thrust loads and torque at extreme conditions.

- A spectral analysis of the thrust signal indicated that the composite BT blades induced slightly higher fluctuating loads on the stanchion. Although these fluctuations are small compared to those reported in literature for rigid blades in dynamic flows (i.e. waves), further investigation is needed to quantify the behavior of BT coupled blades in dynamic flows.

- Verification of a FEM-BEMT design tool showed it to predict the hydrodynamic performance of a turbine with BT blades to within $8 \%$ for TSRs above 2.5 . However, the model performed less well at low TSRs, which is likely due to limitations in lift and drag modelling at low Reynolds numbers. These verification results were considered reasonable, leading to increased confidence in the design tool which facilitates further analysis of HATTs with BT composite blades. Future work will focus on performance predictions for a full-scale turbine with BT composite blades.

- The design objective for the BT blades tested herein was to maximize the thrust load reductions while meeting conservative strength requirements. In this case, a safety factor of 4 (based on Tsai-Hill failure theory) was chosen for the blade design due to the risk associated with performing hydrodynamic tests for the first time. As well, at the time that these blades were designed, the tool had not yet been verified. With the successful verification of the design tool, future BT blades will be designed with lower safety factors which will enable greater thrust load reductions.

- The design tool was computationally efficient, predicting the performance of a HATT with BT blades over a range of TSRs in less than 10 minutes on a standard engineering desktop computer, making it advantageous for early stage design.

\section{ACKNOWLEDGMENTS}

The authors thank Tim O'Doherty, Matt Allmark, Carwin Frost, Allan Mason-Jones, and the team at Cardiff University for providing their turbine and assisting in towing tank and turbine set-up and testing. Thank you also to Thomas Nevalainen for the use of his BEMT code and to Katie Gracie for assisting in the testing. The authors also thank Edd Nixon, Grant Dunning, Sandy Day, Charles Keay, and the team at the Kelvin Hydrodynamics facility for their support during towing tank testing. Finally, the authors thank Altair Engineering Inc. for FEM support, Airborne Marine (Netherlands) for blade manufacturing, Natural Sciences and Engineering Research Council of Canada, Killam Trust, Offshore Energy Research Association of Nova Scotia, United Kingdom Science and Innovation, and Scottish Development International for funding. 
1. Evans, G. Maintaining Marine Turbines. [Online] 2013; Available from: http://www.powertechnology.com/features/feature-maintaining-marine-turbines-tidal-energy/.

2. Liu, P. and B. Veitch, Design and Optimization for Strength and Integrity of Tidal Turbine Rotor Blades. Energy, 2012. 46: p. 393-404.

3. Failed Tidal Turbine Explained at Symposium. CBC News [Online] 2014; Available from: http://www.cbc.ca/news/canada/nova-scotia/failed-tidal-turbine-explained-at-symposium-1.1075510.

4. Turbines, M.C. Delay in Commissioning One of Seagen's Rotors. [Online] July 22, 2008; Available from: http://www.marineturbines.com/3/news/article/11/delay_in_commissioning_one_of_seagen_s_rotors.

5. King, J. and T. Tryfonas. Tidal Stream Power Technology-State of the Art. in Proc. Oceans. 2009. Bremen.

6. Sujeet Swami, P.S., Dharmendra Kumar Jain, Performance of Pitch and Stall Regulated Tidal Stream Turbines. Int. Journal of Engineering Research and Applications, 2014. 4(4): p. 50-53.

7. Thake, J., Development, Installation and Testing of a Large Scale Tidal Current Turbine C.I. Power. 2005.

8. Wood, R.J., A.S. Bahaj, S.R. Turnock, L. Wang, and M. Evans, Tribological Design Constraints of Marine Renewable Energy Systems. Philos Trans A Math Phys Eng Sci, 2010. 368(1929): p. 4807-27.

9. Delorm, T.M., D. Zappala, and P.J. Tavner, Tidal Stream Device Reliability Comparison Models. Proceedings of the Institution of Mechanical Engineers, Part O: Journal of Risk and Reliability, 2011. 226(1): p. 6-17.

10. McEwen, L.N., Evans, R. and Meunier, M. Cost-Effective Tidal Turbine Blades. in 4th International Conference on Ocean Energy, ICOE. 2012. Dublin.

11. Xiao, J.R., B.A. Gama, and J.W. Gillespie, Progressive Damage and Delamination in Plain Weave S-2 Glass/Sc-15 Composites under Quasi-Static Punch-Shear Loading. Composite Structures, 2007. 78(2): p. 182-196.

12. Grogan, D.M., S.B. Leen, C.R. Kennedy, and C.M. Ó Brádaigh, Design of Composite Tidal Turbine Blades. Renewable Energy, 2013. 57: p. 151-162.

13. Mohan, M. The Advantages of Composite Material in Marine Renewable Energy Structures. in RINA Marine Renewable Energy Conference. 2008.

14. Nicholls-Lee, R.F., Adaptive Composite Blades for Horizontal Axis Tidal Turbines, Doctor of Philosophy Thesis School of Engineering Sciences, Southampton, 2011.

15. Motley, M.R. and R.B. Barber, Passive Control of Marine Hydrokinetic Turbine Blades. Composite Structures, 2014. 110: p. 133-139.

16. Barber, R.B. and M.R. Motley. A Numerical Study of the Effect of Passive Control on Cavitation for Marine Hydrokinetic Turbines. in EWTEC. 2015. Nantes, France.

17. Schottel, Schottel Tidal Generator-Scalable Power from Currents Stg-Schottel Tidal Generator. 2013.

18. Wada, H., H. Murayama, and Y. Minami. Deformation Evaluation of Elastic Composite Blade Models for Tidal Power Generation by Fluid-Structure Interaction Analysis. in 18th International Conference on Composite Materials. 2011.

19. Murray, R.E., D.A. Doman, and M.J. Pegg, Finite Element Modeling and Effects of Material Uncertainties in a Composite Laminate with Bend-Twist Coupling. Composite Structures, 2015. 121: p. 362-376.

20. Clarke, J.A., J. Cockroft, A.D. Grant, C.M. Johnstone, T. McCombes, S. Barrett, B. Holmes, A.S. Bahaj, and L. Myres, Equimar Deliverable 3.2 Concept Appraisal and Tank Testing Practices for 1st Stage Prototype Devices, in Equitable Testing and Evaluation of Marine Energy Extraction Devices in terms of Performance, Cost and Environmental Impact 2009.

21. Allmark, M., 2016. PhD Thesis, Cardiff University.

22. Rexroth Indradyn T Synchronous-Torquemotors, Handbook.

23. Ordonez-Sanchez, S., K. Porter, C. Frost, M. Allmark, C. Johnstone, and T. O'Doherty. Effects of WaveCurrent Interactions on the Performance of Tidal Stream Turbines. in Asian Wave and Tidal Energy Conference 2016.

24. Doman, D.A., R.E. Murray, M.J. Pegg, K. Gracie, C.M. Johnstone, and T. Nevalainen, Tow-Tank Testing of a 1/20th Scale Horizontal Axis Tidal Turbine with Uncertainty Analysis. International Journal of Marine Energy, 2015. 11: p. 105-119.

25. Murray, R.E., Passively Adaptive Tidal Turbine Blades: Design Methodology and Experimental Testing, $\mathrm{PhD}$ Thesis, Mechanical Engineering, Dalhousie University, 2016. 
26. Kooijman, H.J.T., Bending-Torsion Coupling of a Wind Turbine Rotor Blade, F.o.A.E.o.t. TUD, Editor. 1996.

27. Kaw, A.K., Mechanics of Composite Materials. Second ed, ed. T.F. Group. 2006: CRC Press Taylor \& Francis Group.

28. Schubel, P.J. and R.J. Crossley, Wind Turbine Blade Design. Energies, 2012. 5(12): p. 3425-3449.

29. Sicomin, Sicomin Foaming Epoxy: Pb 170, Pb 250, Pb 400, Pb 600 Cellular Epoxy Foam Production System. 2009.

30. Milne, I.A., A.H. Day, R.N. Sharma, and R.G.J. Flay, Blade Loading on Tidal Turbines for Uniform Unsteady Flow. Renewable Energy, 2015. 77: p. 338-350.

31. Murray, R.E., T. Nevalainen, K. Gracie-Orr, D.A. Doman, M.J. Pegg, and C.M. Johnstone, Passively Adaptive Tidal Turbine Blades: Design Tool Development and Initial Verification. International Journal of Marine Energy, 2016. 14: p. 101-124.

32. Altair Engineering, Altair Radioss 12.0 User Guide. 2013.

33. Song, B., W. Chen, and W.Y. Lu, Compressive Mechanical Response of a Low-Density Epoxy Foam at Various Strain Rates. Journal of Materials Science, 2007. 42(17): p. 7502-7507.

34. Alonso, M.V., M.L. Auad, and S. Nutt, Short-Fiber-Reinforced Epoxy Foams. Composites Part A: Applied Science and Manufacturing, 2006. 37(11): p. 1952-1960.

35. Maheri, A., S. Noroozi, and J. Vinney, Application of Combined Analytical/Fea Coupled Aero-Structure Simulation in Design of Wind Turbine Adaptive Blades. Renewable Energy, 2007. 32(12): p. 2011-2018.

36. Nevalainen, T., C. Johnstone, and A. Grant. Characterising Unsteady Eccentric Loads on Tidal Stream Turbines Using a Dynamic Blade Element Momentum Theory. in EWTEC. 2015. Nantes, France.

37. Glauert, H., Airplane Propellers. Aerodynamic Theory. 1935: Springer Berlin Heidelberg.

38. Masters, I., and Orme, J.A.C., A Robust Blade Element Momentum Theory Model for Tidal Stream Turbines Including Tip and Hub Loss Corrections. Marine Engineering and Technology, 2011. 10(1): p. 25-36.

39. Shen, W.Z., R. Mikkelsen, J.N. Sørensen, and C. Bak, Tip Loss Corrections for Wind Turbine Computations. Wind Energy, 2005. 8(4): p. 457-475.

40. Chapman, J.C., I. Masters, M. Togneri, and J.A.C. Orme, The Buhl Correction Factor Applied to High Induction Conditions for Tidal Stream Turbines. Renewable Energy 2013. 60: p. 472-480.

41. Spera, D.A., Wind Turbine Technology: Fundamental Concepts of Wind Turbine Engineering. 1994: American Society of Mechanical Engineers.

42. Drela, M., Xfoil 6.94 User Guide. 2001.

43. Batten, W.M.J., A.S. Bahaj, A.F. Molland, and J.R. Chaplin, Experimentally Validated Numerical Method for the Hydrodynamic Design of Horizontal Axis Tidal Turbines. Ocean Engineering, 2007. 34(7): p. 1013-1020.

44. Milne, I.A., An Experimental Investigation of Turbulence and Unsteady Loading on Tidal Turbines, Doctor of Philosophy in Mechanical Engineering, The University of Auckland, 2014. 256.

45. Togneri, M., I. Masters, R. Malki, and A. Rio, Flume Measurements of Lift and Drag for Selected Tidal Turbine Blade Sections. Under review, 2015.

46. Lissaman, P.B.S., Low-Reynolds-Number Airfoils. Ann. Rev. Fluid Mech, 1983. 15: p. 223-239.

47. Harrison, J., R. Howell, G. Manson, C. Sequeira, and P. Vigars, An Evaluation of Steady Radial Flow Modelling for Horizontal Axis Tidal Turbines, in EWTEC. 2015: Nantes, France.

48. McCombes, T., C. Johnstone, B. Holmes, L.E. Myers, A.S. Bahaj, and J.P. Kofoed, Equimar Deliverable 3.4 Best Practice for Tank Testing of Small Marine Energy Devices, in Equitable Testing and Evaluation of Marine Energy Extraction Devices in terms of Performance, Cost and Environmental Impact 2010.

49. International Towing Tank Conference, Recommended Procedures and Guidelines: Guide to the Expression of Uncertainty in Experimental Hydrodynamics. 2008.

50. International Towing Tank Conference, Recommended Procedures and Guidelines Uncertainty Analysis and Instrument Calibration. 2008.

51. Milne, I.A., A.H. Day, R.N. Sharma, and R.G.J. Flay, Blade Loads on Tidal Turbines in Planar Oscillatory Flow. Ocean Engineering, 2013. 60: p. 163-174.

52. Galloway, P.W., L.E. Myers, and A.S. Bahaj. Studies of a Scale Tidal Turbine in Close Proximity to Waves. in 3rd International Conference on Ocean Energy. 2010. Bilbao, Spain. 
660

661

662

663

664

665

666
53. Tatum, S., M. Allmark, C. Frost, D. O’Doherty, A. Mason-Jones, and T. O’Doherty, Cfd Modelling of a Tidal Stream Turbine Subjected to Profiled Flow and Surface Gravity Waves. International Journal of Marine Energy, 2016.

54. Masters, I., A. Williams, T. Croft, M. Togneri, M. Edmunds, E. Zangiabadi, I. Fairley, and H. Karunarathna, A Comparison of Numerical Modelling Techniques for Tidal Stream Turbine Analysis. Energies, 2015. 8(8): p. 7833-7853. 